\title{
Sulla presenza di Seneca nelle opere di Schopenhauer
}

\author{
Sobre a presença de Sêneca nas obras de Schopenhauer
}

\author{
Andrea Musio \\ Dottore di ricerca in "Filologia ed Ermeneutica del Testo" \\ presso l'Università del Salento \\ E-mail: andrewm983@yahoo.it
}

\begin{abstract}
Riassunto: Il presente contributo mira a definire un quadro il più possibile semplice e lineare dei rapporti intercorrenti tra il pensiero di Schopenhauer e quello dello scrittore latino Lucio Anneo Seneca, attraverso l'analisi delle citazioni presenti negli scritti schopenhaueriani editi. Per quanto l'approccio del filosofo di Danzica manchi, a volte, di rigore filologico e, ancor più spesso, di contiguità rispetto al contesto da cui le idee sono estrapolate, non si può che rilevare una conoscenza ampia, organica, approfondita dell'opera senecana, verso cui nutre una sincera ammirazione, come si evince dalla natura e dalla quantità dei testi citati, oltre che da alcune notazioni che li accompagnano. Il criterio seguito nella strutturazione del contributo è quello cronologico, in base al quale ogni paragrafo è dedicato alle citazioni contenute in una specifica opera schopenhaueriana.
\end{abstract}

Parole-chiave: Schopenhauer; Seneca; Citazioni.

Resumo: O presente artigo busca definir um quadro o mais completo e linear possível das relações decorrentes entre o pensamento de Schopenhauer e do escritor latino Lúcio Aneu Sêneca, por meio da análise das citações presentes nos escritos publicados de Schopenhauer. Embora, às vezes, falte à abordagem do filósofo de Danzig rigor filológico e, de modo ainda mais frequente, uma contiguidade em relação ao contexto no qual as ideias estão inseridas, não se pode senão evidenciar um conhecimento amplo, orgânico, aprofundado da obra de Sêneca, pela qual Schopenhauer nutre uma sincera admiração. Isso fica claro pela natureza e pela quantidade dos textos citados, além de algumas notas que os acompanham. O presente texto segue um critério cronológico, com o qual cada parágrafo do artigo é dedicado às citações de Sêneca presentes em uma obra específica de Schopenhauer.

Palavras-chave: Schopenhauer; Sêneca; Citações.

"Se mi è permesso consigliarti una lettura, che ti riporta all'antichità e, al tempo stesso, ti fa pensare a Schopenhauer, prendi le Epistulae morales di Seneca" ${ }^{\text {". Così }}$ scrive Nietzsche all'amico Carl von Gersdorff. E, di sicuro, non si riferisce alla pur ragguardevole quantità di passi senecani che Schopenhauer cita all'interno delle sue opere, e che noi ci proponiamo di analizzare e contestualizzare. L'affinità tra lo scrittore

1 NIETZSCHE, F. Lettera 538 (Lipsia, 20 febbraio 1867), in Epistolario 1850-1869, Vol. I, p. 505. 
più moderno della letteratura latina e il Saggio di Francoforte travalica la semplice citazione, per farsi, in diverse occasioni, solida identità di pensiero.

Il ricorso all'auctoritas dei classici, del resto, è una costante degli scritti schopenhaueriani e deriva da una formazione intensamente nutrita di testi greci e latini: il giovane Arthur non si accontenta di quelli studiati al cospetto dei suoi insigni maestri (solo per il latino, prima il Döring, poi il Passow e a seguire gli stessi direttori dei ginnasi di Weimar e Gottinga), ma li legge con incontenibile avidità in ogni momento libero, quasi non riesce ad arginare la sua continua esigenza di assorbire in toto quello spirito e quella cultura, al punto da trascorrere volutamente il biennio weimariano a casa del Passow, anziché nella residenza materna.

La sua sicurezza nel padroneggiare la letteratura classica lo induce, spesso, a citare mnemonicamente, o comunque a sacrificare la scrupolosità filologica nel rispetto della lezione attestata a vantaggio del valore funzionale che in quel momento la citazione stessa può assumere rispetto al suo discorso. In più di una circostanza, tra le tante prese in esame nel contributo, il filosofo di Danzica varia il testo senecano nelle forme flessive, lo colloca in un locus diverso da quello effettivo, oppure ne astrae il contenuto rendendolo oggetto di interpretazioni più o meno libere (si pensi, per esempio, al Mondo - l'opera nella quale, comprensibilmente, Seneca ricorre con frequenza maggiore - e al fraintendimento della massima per cui ogni magnum ingenium richiede una mixtura dementiae ${ }^{2}$, o al riadattamento in chiave gnoseologica del monito si vis tibi omnia subicere te subice rationi ${ }^{3}$ ).

Leggerezze di questo tipo, che nascono comunque dalla fiducia in un patrimonio cognitivo reale e incontestabile, non riescono tuttavia a scalfire lo spessore dello Schopenhauer lettore di Seneca. La ragione è la stessa alla base del consiglio elargito da Nietzsche. Al di là della smisurata vastità dei temi in merito ai quali il filosofo del Mondo dimostra di conoscere, ammirare, e condividere la filosofia del suo autore, esiste un misterioso fil rouge che scavalca le limitanti strettoie di filtri teoretici e categorie dottrinali per legare stoicismo senecano e pessimismo schopenhaueriano, stretti e diluiti l'uno nell'altro, in un comune sentire grondante ineluttabilità e rassegnazione: nonostante gli oltre mille e settecento anni che li dividono, ritroviamo i due pensatori

2 SENECA, L. A. (d'ora in poi, SEN.) De tranquillitate animi (d'ora in poi, tr. an.), 17, 10, p. 246.

3 SEN., Epistulae ad Lucilium (d'ora in poi, ep.), 37, 4, Vol. I, p. 101. 
intenti a esplorare e a illuminare lo stesso vuoto di senso in cui sembra risolversi la nostra vita, e nel quale ogni nostro progetto e desiderio fluttua senza mai incrociare, fosse anche per un solo istante, la volontà che muove l'universo. L'idea totalizzante, demiurgica, perturbante della volontà schopenhaueriana incontra la percezione dei limiti dell'umana esistenza instillata dalle pagine del Cordovese, nel segno comune di una conquista intellettuale dal sapore amaro, ma illuminante per i lettori di ogni tempo.

\section{§ 1: La quadruplice radice del principio di ragion sufficiente}

Un primo richiamo alle parole del Cordovese si staglia fra le battute conclusive de La quadruplice radice del principio di ragion sufficiente, nella sua forma originaria del 1813 che procura al giovane Arthur la Promotion in filosofia all'Università di Jena.

Gettando le basi per un ridimensionamento in senso strumentale delle nozioni di "fantasia" e "ragione" rispetto alla tradizione precedente inscrivibile tra Cartesio e Kant, il filosofo di Danzica dichiara di volersi limitare ad arare il terreno in vista di un discorso più organico e approfondito. Quest'ultimo atterrà, per forza di cose, alle sfere speculative dell'estetica e dell'etica, che dei due concetti richiamati costituiscono l'humus naturale: l'intento di indagare la reale essenza dell'artista e del santo, considerati fino a quel momento massime espressioni rispettivamente della fantasia e della ragione, potrebbe trovare - come in effetti troverà - pieno riscontro in un'opera successiva, legata alla dissertazione giovanile dallo stesso rapporto che lega la veglia al sogno ${ }^{4}$. Si insinua, in questa immagine, il pattern filosofico che fa un sogno della vita stessa, in balia dell'apparenza e tale da nullificare ogni sforzo compiuto dall'uomo: non sono trascorsi molti anni da quando Goethe - che di lì a poco diventerà il mentore del giovane Arthur, conosciuto nel salotto intellettuale di sua madre Johanna a Weimar ${ }^{5}$ - ha affidato tale pensiero alla penna del suo Werther, in apertura della lettera del 22 maggio $1771^{6}$. Perché il lettore non sia però indotto dal parallelo tra sonno e veglia a svilire lo scritto quasi concluso, Schopenhauer si appella all'assunto senecano per cui somnia

4 SCHOPENHAUER, A., La quadruplice radice del principio di ragione sufficiente (1813), § 58, p. 165. $5 \mathrm{Sul}$ rapporto che lega Goethe a Schopenhauer e sulla sua evoluzione, vd. DIRRIGL, M., Goethe und Schopenhauer: mit zwei Excursen, passim; LAUXTERMANN, P.F.H., Schopenhauer's Broken WorldView. Colours and ethics between Kant and Goethe, passim.

6 GOETHE, J. W., I dolori del giovane Werther, p. 429. 
narrare vigilantis est ${ }^{7}$. La citazione offre già un chiaro sentore del valore squisitamente funzionale che il testo latino può assumere per il Saggio di Francoforte, a scapito, talvolta, del rigore filologico, che in questo caso avrebbe imposto il rispetto della lezione somnium, attestata persino da Ruhkopf $^{8}$, autore dell'edizione di riferimento per le Epistulae ad Lucilium in possesso del filosofo ${ }^{9}$. Emerge altresì la tendenza a una certa decontestualizzazione rispetto al discorso in cui la citazione si inquadra, se si tiene conto che, all'interno del testo considerato, il sogno diventa metafora del vizio - non certo veicolo di alcunché di positivo - e la veglia di quell'attenzione razionale, di quella costante presenza rispetto a se stessi e alle proprie azioni che solo la pratica filosofica è in grado di garantire. A confermare questa valenza deprecabile del sogno allegoricamente inteso si dipanano nei Dialogi alcuni pensieri che vi colgono, tra l'altro, la pochezza morale ed esistenziale di chi trascorre la vita accumulando ricchezze ${ }^{10}$, oppure la vacuità attribuita dal saggio alle offese gratuite che gli vengono rivolte ${ }^{11}$ La veglia, dal canto suo, è - come emerge dalle Lettere - la stessa che consente di ravverdersi dei propri errori sancendo un solido progresso dell'animo ${ }^{12}$, nonché di esercitare verso se stessi prima il ruolo di accusatori, poi di giudici, infine di avvocati, all'occorrenza anche di punitori ${ }^{13}$. In questa prospettiva, il sognatore, il dormiente resta bloccato nella sua atavica e pervicace incapacità di vedere ciò che è sotto gli occhi di tutti, contemporanei e posteri, decretando per se stesso un impietoso verdetto di condanna da parte della storia: questo è, ad esempio, il giudizio con cui Cicerone inchioda Marco Antonio nella seconda Filippica, apostrofandolo come miser perché non si rende conto di aver causato una guerra col suo comportamento scellerato ${ }^{14}$, miseriorem perché non realizza quanto esso ne vada a inficiare la memoria nei secoli a venire.

7 SEN. ep. 53, 8, Vol. I, p. 141.

8 RUCKOPF, F. E. (ed.), L. Annaei Senecae philosophi opera omnia quae supersunt. Recognovit et illustravit Fridericus Ernestus Ruhkopf, Vol. II, p. 231.

9 Per le edizioni delle opere senecane impiegate da Schopenhauer, vd. HÜBSCHER, A., (hrsg. v.), Arthur Schopenhauer. Der handschriftliche Nachlaß in fünf Bänden - Bd. 5: Randschriften zu Büchern, p. $163 \mathrm{~s}$. 10 SEN., De providentia (d'ora in poi, prov.), 6, 3, p. 58.

11 SEN., De costantia sapientis (d'ora in poi, const. sap.).

12 SEN. ep. 6, 1, Vol. I, p. 10.

13 SEN. ep. 28,9 s., Vol. I, p. 81.

14 CICERO, M. T., Philippicae, 2, 22, 54, p. 56. Il riferimento è soprattutto al veto espresso nel 50 da Antonio, in qualità di tribuno, al decreto per dichiarare Cesare hostis publicus. Per quanto l'Arpinate individui nella sola persona di Antonio causa perniciosissimi belli, Cesare (CAESAR, De bello civili, 1 , 2, 6, p. 2) attribuisce il veto tribunizio anche a Cassio. 
Schopenhauer sceglie, in questa sede, un enunciato senecano che gode di una notevole fortuna.

Il Petrarca lo cita nella lettera che apre il secondo libro delle Senili ${ }^{15}$, indirizzata a Giovanni Boccaccio e relativa alla richiesta di pubblicare l'Africa, avanzata, tra gli altri, da un funzionario della corte di Napoli, Barbato da Sulmona, reo di aver divulgato, vent'anni prima, trentaquattro versi del poema che l'autore stesso gli aveva concesso di leggere, in seguito alle sue pressanti insistenze, dietro la promessa di tenerli segreti. Ne seguirono travisamenti e aspre critiche, dovute per lo più - dal punto di vista del poeta a invidie e calunnie maturate in seno all'ambiente fiorentino. I versi incriminati erano relativi al momento della morte di Magone, figlio di Amilcare e fratello di Annibale, durante la seconda guerra punica, e il Petrarca menziona le parole di Seneca rispondendo alla seconda accusa rivoltagli dai detrattori, quella cioè di aver attribuito a un personaggio pagano in fin di vita pensieri e discorsi propri della più autentica mentalità cristiana: "raccontare un sogno" diventa dunque allegoria della più attenta autoanalisi e, in definitiva, della confessione, che incarna sì un atto investito di una luce sacrale, ma non può essere oppresso nelle limitanti strettoie di uno specifico credo religioso (come attesta il fatto che sia lo stesso Seneca a parlarne ${ }^{16}$ ).

Il Montaigne non è da meno e, del resto, Seneca è un autore che sente particolarmente vicino, almeno quanto il filosofo di Danzica, al punto da citarlo talvolta come "mon Sénèque"17. Passando in rassegna gli insegnamenti appresi con l'età avanzata, elogia il coraggio della confessione dei propri vizi e stigmatizza la cecità di chi non riesce a riportarli alla luce: è qui che torna la stessa citazione, e il valore attribuitole resta sostanzialmente invariato ${ }^{18}$.

Nel corso del Seicento, l'enunciato senecano gode di un singolare successo nei testi, spesso a carattere parenetico, di alcuni religiosi anglicani, i quali istituiscono un legame costante tra il sogno e il peccato: ricordiamo William Laud, arcivescovo di

15 PETRARCA, F., Rerum senilium libri, 2, 1, 29, p. 178.

16 A rendere ancor più inequivocabile il senso del pensiero senecano sono le parole immediatamente successive a quelle citate: ... et vitia sua confiteri sanitatis iudicium est (ep. 53, 8, Vol. I, p. 142).

17 Sulla presenza di Seneca in Montaigne, vd. CHEVALLIER, R., Montaigne, Lecteur de Sénèque, pp. 95 ss.

18 DE MONTAIGNE, M., Saggi, III, 5, p. 875. 
Canterbury ${ }^{19}$, Robert Leighton, arcivescovo di Glasgow - il quale giunge ad affermare che "il sonno è fratello della morte"20 - e il predicatore Richard Baxter"

A incorrere in un lieve equivoco interpretativo sarà Kierkegaard, il quale, traducendo molto probabilmente in modo autonomo il testo latino, per esprimere la nozione contenuta in vigilans impiegherà la parola danese Vaagnende ${ }^{22}$, che si addice a un individuo ancora in procinto di svegliarsi, piuttosto che a uno intento, nel pieno della sua lucidità, a illuminare gli oscuri meandri della propria coscienza.

Al di là di quest'unica ricorrenza nel corpo del trattato, il riferimento a Seneca torna nella Vorrede alla seconda edizione dello stesso, risalente al 1841, laddove Schopenhauer sottolinea la necessità di una nuova distribuzione dello scritto, sia per la sua definitiva assenza dal mercato librario sia per una doverosa revisione dell'opera che, in modo un po' inaspettato, ha finito per incarnare la colonna portante del suo sistema ${ }^{23}$. Il Saggio di Francoforte dichiara di esser consapevole del poco tempo rimastogli per emendare in qualunque modo la sua produzione precedente, ma anche della forza che si estrinsecherà da quelle pagine dopo la sua morte, quando subentrerà la vera azione della sua filosofia: a corroborare questa certezza è il principio senecano per cui etiam si omnibus tecum viventibus silentium livor indixerit, venient qui sine offensa, sine gratia iudicent ${ }^{24}$. Si tratta dell'ideale del riconoscimento da parte dei posteri, che, se non è radicato nel veterostoicismo (Cicerone, nel De finibus ${ }^{25}$, ricorda che Crisippo e Diogene rifiutano di considerarlo un valore positivo), di sicuro è accolto in una fase successiva del pensiero stoico: lo stesso Seneca definisce id quod nostris placet la percezione della claritas quae post mortem contingit come bonum ${ }^{26}$. Che poi l'apertura stoica rispetto a questa idea avvenga in modo pieno e completo con Antipatro o con Panezio è materia alquanto dibattuta, e anche Cicerone è molto vago, inizialmente, nell'attribuire la riscoperta della bona fama fra i vivi a una nuova generazione di stoici collocabili dopo i

19 LAUD, W., Sermon of the fast day, p. 129.

20 LEIGHTON, R., Sermon I (Romans XIII 11-14), p. 507.

21 BAXTER, R., The mischiefs of self-ignorance, and benefits of self-acquaintance, p. 52.

22 KIERKEGARD, S., Skrifter, NB17:104, p. 245.

23 SCHOPENHAUER, A., Prefazione a La quadruplice radice del principio di ragione sufficiente (1841), p. 19.

24 SEN. ep. 79, 17, Vol. I, p. 260.

25 Cfr. CICERO, M. T. (d'ora in poi, CIC.), De finibus bonorum et malorum (d'ora in poi, fin.), 3, 57, p. 111: de bona autem fama (...) Chrysippus (...) et Diogenes detracta utilitate ne digitum quidem eius causa porrigendum esse dicebant.

26 SEN. ep. 102, 3, Vol. II, p. 102. 
maestri fondatori ${ }^{27}$ (nel De officiis, però, un'ampia divagazione sul tema della gloria si apre e si chiude proprio nel segno di Panezio ${ }^{28}$ ). A ogni buon conto, è evidente che lo stoicismo romano si appropri in toto di questo ideale, se consideriamo che sempre l'Arpinate qualifica gloria virtutis rerumque gestarum come l'eredità più preziosa che un padre possa lasciare al proprio figlio ${ }^{29}$. Un pensiero ancor più attinente con la citazione di Schopenhauer - con un simile ma più sottile riferimento alla serenità dell'animo chi giudica - è quello che vede nella gloria consentiens laus bonorum, incorrupta vox bene iudicantium de eccellenti virtute ${ }^{30}$ (in queste parole Pohlenz, ignorando le esplicite indicazioni fornite dall'autore e ricordate poc'anzi, coglie discutibilmente un influsso crisippeo ${ }^{31}$ ). Ma ancor prima - e qui l'analogia col concetto schopenhaueriano e con l'asserto mutuato da Seneca raggiunge l'apice dell'evidenza Cicerone dichiara che, per quanti non credono nell'immortalità dell'anima e sono sul punto di esalare il loro ultimo respiro, non c'è consolazione più grande del pensiero di un'altra vita oltre la morte, assicurata dalla permanenza delle loro azioni e dei loro pensieri $^{32}$. Dopodiché, aggiunge: etsi enim nihil habet in se gloria cur expetatur, tamen virtutem tamquam umbra sequitur ${ }^{33}$. Anche questa affermazione è ripresa quasi alla lettera da Seneca nella stessa epistola a cui attinge Schopenhauer (gloria umbra virtutis est: etiam invitam comitabitur ${ }^{34}$ ). A rafforzare, a tal riguardo, il legame tra il Cordovese e Schopenhauer è il fatto che, sempre nell'epistolario, anche il modello trasli il discorso

27 Ibid.: qui autem post eos (scil. Chrysippus et Diogenes ) fuerunt, cum Carneadem sustinere non possent, hanc quam dixi bonam famam ipsam propter se praepositam et sumenda esse dixerunt (...) dicuntque, ut liberis consultum velimus, etiamsi postumi futuri sint, propter ipsos, sic futurae post mortem famae tamen esse propter rem, etiam detracto usu, consulendum. Dietro l'espressione qui post eos fuerunt, SCHÄFER (Ein frühmittelstoisches System der Ethik bei Cicero: Untersuchung von Ciceros drittem Buche De finibus bonorum et malorum, nach Aufbau und Zugehörigkeit auf Grund griechischer Quellen zur stoischen Ethik, pp. 155 ss.) ritiene di poter cogliere un chiaro riferimento ad Antipatro, mentre PHILIPPSON (Rezension zu M. Schäfer, Ein frühmittelstoisches System der Ethik bei Cicero, p. 593) vi ravvisa il rimando a Panezio.

28 Il Rodiese è menzionato in De officiis (d'ora in poi off.) 2, 35, p. 61 e 51, p. 66, prima come modello per il linguaggio da adottare quando si discorre dell'opinione popolare, poi come termine di confronto per la valutazione dell'uso del discorso e del ragionamento in contesti giuridici, sempre nella prospettiva del giudizio della collettività.

29 Cfr. CIC. off. 1, 121, p. 37: optima autem hereditas a patribus traditur liberis omnique patrimonio praestantior gloria virtutis rerumque gestarum, cui dedecori esse nefas et vitium iudicandum est.

30 CIC., Tusculanae disputationes (d'ora in poi, Tusc.), 3, 3, Vol. II, p. 5.

31 POHLENZ, M., La Stoa, Vol. I, p. 564 n. 31.

32 Cfr. CIC. Tusc. 1, 109, Vol. I, p. 121: (...) si ipsa ratio minus perficiet, ut mortem neglegere possimus, at vita acta perficiat, ut satis superque vixisse videamur. quamquam enim sensus abierit, tamen suis et propriis bonis laudis et gloriae, quamvis non sentiant, mortui non carent.

33 Ibid.

34 SEN. ep. 79, 13, Vol. I, p. 259. 
alla prima persona, facendone quasi un argomento consolatorio rivolto a se stesso, in un momento - quale quello della sua maturità - in cui sente incombere il rischio della damnatio memoriae ${ }^{35}$ : posterorum negotium ago. Illis aliqua quae possint prodesse $\operatorname{conscribo}^{36}$, scrive Seneca in una lettera il cui fulcro tematico, non a caso, è la filosofia con la sua forza eternatrice.

\section{§ 2: Il mondo come volontà e rappresentazione}

La prima occorrenza delle parole senecane nel Mondo si registra all'interno di un paragrafo del primo libro che rappresenta una sintesi perfetta della concezione schopenhaueriana sulle dimensioni dello spazio e del tempo, abbastanza affine, come noterà Nietzsche ${ }^{37}$, a quella di Eraclito. Per il filosofo di Danzica, spazio e tempo costituiscono le forme intuitive dell'umana percezione della realtà materiale, le coordinate su cui si realizza l'azione della materia, che coincide con l'essenza di quest'ultima e che si esplica attraverso il rapporto causa - effetto ${ }^{38}$. Dopo aver abbondantemente chiarito questo principio, Schopenhauer precisa che il tedesco, per esprimere la sostanza di tutto ciò che è materiale, fa ricorso alla parola Wirklichkeit (da Wirken, "agire", "effettuare"), molto più appropriata del termine Realität: a dimostrazione di come il patrimonio lessicale di una lingua riesca spesso a carpire la quintessenza delle cose che rappresenta, a scandagliarne la natura più intima, a estrapolarne la dimensione filosofica, l'autore cita in nota il monito senecano mira in quibusdam rebus verborum proprietas est, et consuetudo sermonis antiqui quaedam efficacissimis et officia docentibus notis signat ${ }^{39}$.

Per quanto dalle pagine senecane traspaia una diffusa sfiducia di base nelle parole in sé rispetto alle azioni - che potremmo forse paragonare a quella di Pavese nella nostra letteratura e che trova il suo acme nell'affermazione per cui multum ...

35 GIANCOTTI (Seneca personaggio dell'Octavia, p. 75) ravvisa tracce evidenti di questa valenza autobiografica dell'idea del riconoscimento dei propri meriti - a dispetto di possibili calunnie alimentate dai contemporanei - all'interno dell'Octavia attribuita a Seneca, anche nella rilevanza attribuita dall'autore al personaggio di se stesso all'interno della tragedia.

36 SEN. ep. 8,2, Vol. I, p. 14.

37 Cfr. NIETZSCHE, F., La filosofia nell'età tragica dei Greci, § 5, p. 86.

$38 \mathrm{Cfr}$. SCHOPENHAUER, A., Il mondo come volontà e rappresentazione, Vol. I, § 4, p. $130 \mathrm{~s}$.

39 SEN. ep. 81, 9, Vol. I, p. 266. 
operae inpendi verbis non oportet ${ }^{40}$-, la verborum proprietas mantiene sempre una sua rilevanza, in quanto oggetto della logica teso a discernere il vero dal falso ${ }^{41}$ : è proprietas la caratteristica focale che Seneca riconosce nella oratio del maestro Fabiano, di cui loda la securitas, da intendersi come giusta via di mezzo tra sollicitudo e negligentia, come scelta oculata di parole semplici, puntuali e pertinenti, fedeli riflessi di ciò che esprimono ${ }^{42}$. Se la proprietas veicola la nozione veterostoica del $\pi \rho \varepsilon ́ \pi o v^{43}$, è innegabile che il potere mimetico della parola sia oggetto di un'ampia disamina già nei dialoghi platonici: nel Cratilo, per bocca di Socrate, si apre il dibattito sulla effettiva

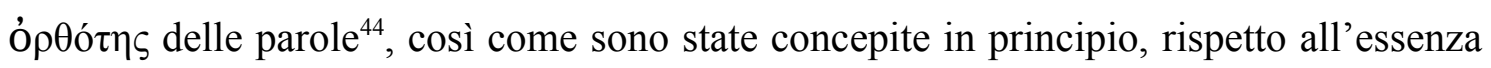
delle cose. Passando attraverso il riconoscimento di una غ́ $\pi i ́ r v o r \alpha^{45}$, di una sorta di divina ispirazione cui soggiace la genesi del linguaggio, la questione trova un definitivo compimento nelle Leggi, dove si sancisce il valore della parola come strumento di controllo dell'infinita molteplicità del reale, in virtù dell'esattezza dei nomi che gli antichi hanno attribuito alle $\cos \mathrm{e}^{46}$.

Alcuni paragrafi più avanti ${ }^{47}$, Schopenhauer contrappone concetti e intuizioni e, dopo averne evidenziato le rispettive ripercussioni sull'arte (per cui è realmente proficua solo la conoscenza che promana dalle seconde), passa ad analizzare gli effetti prodotti nella vita relazionale: anche le intenzioni e le disposizioni d'animo più encomiabili finiscono con l'esser malamente inficiate dal concetto, per sua natura foriero di riflessione. Quest'ultima altera ogni forma di garbo, gentilezza, simpatia, lasciandone percepire l'inautenticità molto prima di quanto si possa immaginare: nemo potest personam diu ferre fictam ${ }^{48}$, scrive Seneca nel De clementia, e Schopenhauer lo ricorda prontamente in questa sede. Il Cordovese impiega queste parole in un'accorata esortazione al giovane Nerone, ravvivata da una metafora che mutua dal contesto

40 SEN. ep. 75, 3, Vol. I, p. 233.

41 Cfr. SEN. ep. 89, 9, Vol. II, p. 327: tertia (scil. partis rationalis) proprietates verborum exigit et structuram et argumentationes, ne pro vero falsa subrepant .

42 Cfr. SEN. ep. 100, 5, Vol. II, p. 418: Fabianus non erat neglegens in oratione sed securus. Itaque nihil invenies sordidum: electa verba sunt, non captata, nec huius saeculi more contra naturam suam posita et inversa, splendida tamen quamvis sumantur e medio.

43 Sul concetto zenoniano del $\pi \rho \varepsilon \dot{\pi}$ ov, cfr. DIOGENES LAERTIUS, Vitae philosophorum (d'ora in poi, DIOG. LAERT.), 7, 59, p. 479 s.

44 PLATO (d'ora in poi, PLAT.), Cratylus, 397b ss., p. 90 s.

45 Ibid. 399a, p. 74.

46 Cfr. PLAT. De legibus (d'ora in poi, Lg.), 816b, Vol. III, p. $52 .$.

47 Cfr. SCHOPENHAUER, A., Il mondo ..., cit., Vol. I, § 12, p. 204.

48 SEN., De clementia (d'ora in poi, clem.), 1, 1, 6, p. 4. 
teatrale. Persona (corrispondente al greco $\pi \rho o ́ \sigma \omega \pi \mathrm{ov}$ ) indica infatti la maschera, simbolo di un'identità mistificata, che, riferita al princeps, si tinge sommessamente di una tragica ironia: il maestro non può immaginare che, nello stesso momento in cui invita il suo allievo a deporre quella maschera che ha reso ficta la bonitas dei suoi predecessori Augusto e Tiberio (menzionati subito prima), gliene stia porgendo una molto più infida e pericolosa, che l'imperatore sfilerà dal volto solo quando realizzerà la lunga serie di turpi misfatti, culminanti con la sua stessa eliminazione. Simile è, nelle Lettere, il consiglio che Seneca dispensa a Lucilio, scagliandosi contro l'incoerenza che tanto, al suo tempo, impesta i rapporti umani e denunciando a chiare lettere: mutamus subinde personam et contrariam ei sumimus quam exuimus ${ }^{49}$. Quando, nel De beneficiis, il Cordovese deplora la sorte di quanti indulgono alle lusinghe della superbia (altrove definita morbus animorum ${ }^{50}$ ), che trasforma in offesa ogni beneficio da loro elargito e li rende talmente miopi da scambiare per grandezza la loro meschinità, il discorso si conclude con un interrogativo dalla disarmante vis demistificatoria: libet itaque interrogare, quid tantopere te resupinet, quid vultum habitumque oris pervertat, ut malis habere personam, quam faciem ${ }^{51}$ Ancora una volta, dunque, persona è il correlato semantico di una natura volutamente e biecamente artefatta. Altrove, l'accezione senecana dell'uso metaforico di persona perde una parte dei suoi connotati negativi, denunciando un'inautenticità che è spia di un'avvilente e atavica debolezza più che di strisciante e malevola simulazione. È ciò che avviene, ad esempio, nel De tranquillitate animi, quando il palcoscenico calcato dalla persona diventa quello di una quotidianità densa di angoscia, dove la maschera pesa come un macigno e lo sguardo altrui fa paura: la metafora si veste di una profonda valenza sociale, mettendo a nudo la crisi dell'uomo di quel tempo ${ }^{52}$, condannato a vivere perennemente $s u b$ persona ${ }^{53}$. Lo

49 SEN. ep. 120, 22, Vol. II, p. 516.

50 SEN. ep. 106, 6, Vol. II, p. 444.

51 SEN, De beneficiis (d'ora in poi, ben.), 2, 13, 1, .

52 È molto illuminante, a riguardo, l'analisi condotta da BARTON (Roman Honor. The fire in the bones, pp. $120 \mathrm{~s}$.), il quale, all'interno di un capitolo convenientemente denominato "Il momento della verità nell'antica Roma", evidenzia come, da un certo punto in poi della vita politica dell'Urbe, la faccia si trasformi in facciata, e la persona passi da un ruolo squisitamente espressivo - quello, cioè, all'interno dei teatri - a uno fondamentalmente difensivo. Tale analisi è opportunamente corroborata da un congruo numero di exempla estrapolati, in parte, dalla narrazione di Livio, ma riguardanti soprattutto l'età imperiale, nei racconti di Tacito e Svetonio.

53 SEN. tr. an. 17, 1, p. 242: est et illa sollicitudinum non mediocris materia, si te anxie componas nec ullis simpliciter ostendas, qualis multorum vita est, ficta, ostentationi parata: torquet enim assidua observatio sui et deprehendi aliter ac solet metuit. Nec umquam cura soluimur, ubi totiens nos aestimari 
smascheramento ha spesso come oggetto la parvenza di felicità che la persona può recare impressa su di sé, come nel caso degli alti dignitari, la cui veste purpurea non li rende, nei fatti, più felici di quanti sul palco indossano scettro e mantello per mere esigenze sceniche ${ }^{54}$. Poco più avanti nell'epistolario il parallelo tra gli attori e i personaggi che sfilano quotidianamente sulla scena dell'Urbe si fa più esplicito e dilatato: proprio le persone ritenute più fortunate nell'immaginario collettivo, in virtù del loro prestigio e delle loro ricchezze, possono celare le più insospettabili miserie, insieme a un cuore attanagliato dalla tristezza. La loro condizione non le rende diverse da quegli attori che sulla scena teatrale prestano il proprio corpo a sembianze maestose e la propria bocca a parole altisonanti tipiche di sovrani e di eroi, quando nella realtà possono essere schiavi o vivere comunque in condizioni di indigenza: è analoga la situazione di coloro che si ergono sulle teste dei concittadini stesi su una lettiga: omnium istorum personata felicitas est $t^{55}$. Quando poi Seneca inizia a trattare le più recondite e diffuse paure umane - quelle della morte e della sofferenza - riconoscendovi gli effetti prodotti dalla maschera, l'atto di rimuoverla diventa una sfida che non ha più come oggetto le sole persone, ma anche le cose, e non investe più la sola dimensione sociale ma anche - e soprattutto - quella intima e individuale: non hominibus tantum sed rebus persona demenda ${ }^{56}$ est et reddenda facies sua, e lo scopo è quello di uscire da una situazione di prostrante infantilismo, che ci associa a quei fanciulli capaci di spaventarsi persino dei loro stessi compagni di giochi, se li vedono personatos $^{57}$. Ma ad associare ancor prima la maschera dell'apparenza alle paure umane è Lucrezio, il quale, in riferimento alla spavalderia di certi individui che millantano una razionalità impavida

putamus quotiens aspici. Nam et multa incidunt quae invitos denudant, et, ut bene cedat tanta sui diligentia, non tamen iucunda vita aut secura est semper sub persona viventium.

54 Cfr. SEN. ep. 76, 31, Vol. I, p. 243: nemo ex istis quos purpuratos vides felix est, non magis quam ex illis quibus sceptrum et chlamydem in scaena fabulae adsignant.

55 SEN. ep. 80, 8, Vol. I, p. 262.

56 Sul tema della persona demenda in Seneca, si rimanda all'interessante analisi condotta da Maria Bellincioni, la quale associa il passo citato, e in particolare il paragone coi bambini e la loro paura delle maschere, a due altri passi senecani, vale a dire const. sap. 5, 2, p. 76 (ad tantas ineptias perventum est ut non dolore tantum sed doloris opinione vexemur, more puerorum, quibus metum incutit umbra et personarum deformitas et depravata facies) e De ira (d'ora in poi, ir.) 2, 11, 2, p. 192 (ira per se deformis est et minime metuenda, at timetur a pluribus sicut deformis persona ab infantibus; su questo passo vd. anche MUSIO, A., [a c. di], Lucio Anneo Seneca, De ira. Libro primo. Testo, introduzione, traduzione e commento di Andrea Musio, p. 190), riconoscendo in questo confronto un topos diatribico, come dimostra il rimando a Epict. diss. 3, 22, 106 (BELLINCIONI, M., Il termine persona da Cicerone a Seneca, p. 67, n. 2).

57 SEN. ep. 24, 13, Vol. I, p. 69. 
della morte - falsa perché priva del sostanziale apporto della filosofia - per poi dimenticarsene quando il buio eterno è ormai dietro l'angolo, osserva lapidariamente: eripitur persona, manet res ${ }^{58}$.

Tornando alla citazione di Schopenhauer, è altresì notevole l'analogia concettuale con la sententia ciceroniana del De officiis per cui nec simulatum potest quicquam esse diuturnum $^{59}$. Nelle Tusculanae, Cicerone impiega nuovamente il termine persona, con la stessa accezione negativa, per qualificare l'ambizione, da parte di Epicuro, allo status di filosofo, del quale, nella realtà dei fatti, non può che vestire la maschera $^{60}$.

La sententia senecana citata da Schopenhauer è infine presente - livemente variata in difficile fictam personam ferre diu ed erroneamente attribuita al corpus tragicum senecano - in uno dei Discorsi di Hobbes focalizzati sul modello politico dell'antica Roma, a proposito di Tiberio Nerone (figlio di Livia Drusilla che ottenne l'adoptio da parte di Augusto nel 4 d. C.), della sua superbia e della sua crudeltà, due vizi che, a lungo andare, emergono con una prepotenza tanto maggiore quanto più si cerca di dissimularli ${ }^{61}$.

Nel paragrafo del Mondo dedicato all'arte e alla genialità ${ }^{62}$, torna la contrapposizione tra la conoscenza razionale, fonte del concetto, e quella intuitiva, nonché il rilievo del ruolo giocato dalla riflessione, promanante dai concetti, nelle interazioni verbali, che ne risultano in qualche modo svilite, perché troppo focalizzate sull'interlocutore - e quindi su ciò che gli si vuole far percepire - piuttosto che sul contenuto. Ebbene, il genio agisce in modo diametralmente opposto, lasciando che sia l'intuizione a veicolare il proprio discorso, mosso perciò da un fermento tedente all'irrazionale e spontaneamente calibrato sulla base di ciò che si dice, e non della persona a cui lo si dice. Il che si traduce in una sostanziale mancanza di filtri, che eclisserà ogni traccia di controllo, di raziocinante costruzione, di studiata ponderatezza, favorirà l'attitudine ai monologhi $\mathrm{e}$, in definitiva, darà luogo a un discorso 58 LUCRETIUS, De rerum natura (d'ora in poi, LUCR.), 3, 58, p. 174. 59 CIC. off. 2,43 , p. 63.

60 Cfr. CIC. Tusc. 5, 73, Vol. II, pp. 136 s.: an Epicuro, qui tantum modo induit personam philosophi et sibi ipse hoc nomen inscripsit (...).

61 HOBBES, T., Discorso sull'inizio degli Annali di Tacito, § 318, trad. it. in D. COLI, Hobbes, Roma e Machiavelli nell'Inghilterra degli Stuart. Con la prima edizione italiana dei Tre Discorsi di Thomas Hobbes, p. 230.

62 SCHOPENHAUER, A., Il mondo ..., cit., Vol. I, § 36, pp. 383 ss. 
Schopenhauer non lo nega - strutturalmente debole: ma è proprio in questa congenita debolezza, talora prossima al delirio, che risiede un tratto distintivo della genialità ${ }^{63}$. È notorio, infatti, come quest'ultima sia incline a intrecciarsi alla follia, e a suffragio di questa conclusione il filosofo di Danzica cita alcune fonti "eccellenti", tra cui Aristotele riletto da Seneca nell'asserto nullum magnum ingenium sine mixtura dementiae fuit ${ }^{64}$. Questo rimando offre un altro esempio della propensione schopenhaueriana a decontestualizzare la citazione rispetto al discorso globale da cui è estrapolata. Seneca, infatti, non contempla la componente della dementia come condizione stabile - o comunque usuale - di una personalità brillante, bensì come eventuale circostanza relegata ai pochi ma doverosi momenti di svago che chiunque dovrebbe concedersi per recare conforto a un animo sopraffatto dalle preoccupazioni: tali momenti possono essere costituiti da una passeggiata all'aria aperta, da qualche viaggio, da qualche bicchiere in più, e anche - occasionalmente - da una sbornia, concepita non come annichilimento della coscienza, ma come affrancamento dalle inquietudini transitorie che impediscono di svolgere $\mathrm{i}$ propri doveri con l'opportuna serenità ${ }^{65}$. È a questo proposito che Seneca cita le opinioni di tre autori concordi nell'indulgere a episodici istanti di pazzia, mai estranei alle menti più feconde: si tratta rispettivamente di un poeta greco del quale non si menziona il nome (nam, sive graeco poetae creduimus “aliquando et insanire iucundum est") ${ }^{66}$, di Platone (sive Platoni, "frustra poeticas fores compos sui pepulit" $)^{67} \mathrm{e}$, appunto, di Aristotele, che il Cordovese riporta parafrasando un passo dei Problemata physica a lui attribuiti ${ }^{68}$. È curioso constatare come, in realtà, in questo caso sia lo stesso Seneca a decontestualizzare, a sua volta, l'affermazione della sua fonte. Nel paragrafo del trattato aristotelico si affronta il tema

63 Ibid., p. 391.

64 SEN. tr. an. 17, 10, p. 246.

65 Cfr. ibid., 8: indulgendum est animo dandumque subinde otium, quod alimenti ac virium loco sit. Et in ambulationibus apertis vagandum, ut caelo libero et multo spiritu angeat attollatque se animus; aliquando vectatio iterque et mutata regio vigorem dabunt, conuictusque et liberalior potio. Nonnumquam et usque ad ebrietatem veniendum, non ut mergat nos, sed ut deprimat: eluit enim curas et ab imo animum movet et, ut morbis quibusdam, ita tristitiae medetur, Liberque non ob licentiam linguae dictus est inventor vini, sed quia liberat servitio curarum animum et asserit vegetatque et audaciorem in omnes conatus facit.

66 Per la possibile identificazione dell'autore, vd. PASOLI, E., Semel in anno licet insanire, pp. 249 s.; RENEHAN, R., A fragment of Alcaeus in Seneca?, p. 188, n. 1; SETAIOLI, A., Seneca e i greci. Citazioni e traduzioni nelle opere filosofiche, pp. $61 \mathrm{~s}$.

67 Cfr. PLAT. Phaedrus, 245a, p. $32 \mathrm{s.}$

68 Cfr. ARISTOTELES (d'ora in poi, ARIST.), Problemata, 953a, 10 s., vol. III, p. 29. 
della $\mu \varepsilon \lambda \alpha \gamma \chi 0 \lambda i ́ \alpha$ che accomuna i più eminenti protagonisti della filosofia, della politica, della poesia e dell'arte, e che deriva dal loro temperamento atrabiliare (vale a dire dalla presenza nel loro corpo della bile nera); lo Stagirita espone più o meno diffusamente gli esempi di Eracle, Aiace, Bellerofonte tra gli eroi, Lisandro tra i condottieri, Empedocle, Socrate e Platone tra i filosofi, a dimostrazione di come gli effetti della $\mu \varepsilon \lambda \alpha \gamma \chi 0 \lambda i ́ \alpha$ possano essere i più svariati, sia dal punto di vista fisico che da quello comportamentale. Negli individui interessati si registra, difatti, una maggiore inclinazione ai $\pi \alpha \dot{\theta} \eta$, alle affezioni che ne scaturiscono: gli effetti sono simili a quelli di un'assunzione eccessiva di vino, che non hanno segno univoco, per cui alcuni soggetti saranno più irritabili, altri più espansivi, altri ipersensibili, altri imprudenti e sconsiderati, e via dicendo ${ }^{69}$. La follia non è che una di queste possibili manifestazioni. Due, a questo punto, le spiegazioni possibili della parzialità della resa senecana. La prima - che noi, d'accordo con una buona parte della critica ${ }^{70}$ riteniamo maggiormente plausibile - è che quella di Seneca sia una citazione indiretta da probabile fonte dossografica. Ciò emerge con una certa evidenza se si osservano i rimandi allo stesso passo aristotelico nelle Tusculanae di Cicerone $^{71}$ e nella Vita di Lisandro plutarchea ${ }^{72}$, al cui interno è innegabile il riferimento al contesto, al di là della singola citazione: entrambi, infatti, menzionano gli exempla addotti da Aristotele (exempla - lo abbiamo visto - non per forza relativi alla follia), che Plutarco addirittura ricorda nominalmente ${ }^{73}$. La seconda possibilità è che Seneca abbia deliberatamente tradotto $\mu \varepsilon \lambda \alpha \gamma \chi 0 \lambda i ́ \alpha$ con mixtura dementiae ${ }^{74}$ : tale forzatura sarebbe stata indotta o dal bisogno di mantenere una certa coerenza con le citazioni degli altri due autori - riguardanti rispettivamente la liceità dell'insania occasionale e l'inadeguatezza per l'arte poetica di chi è sempre compos sui - oppure dalla

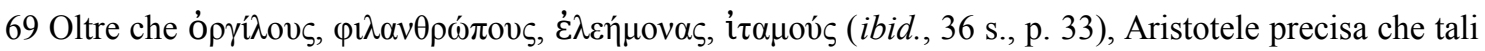

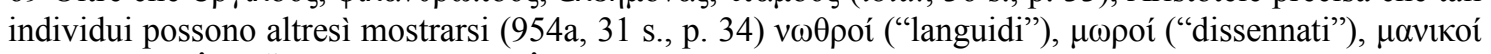

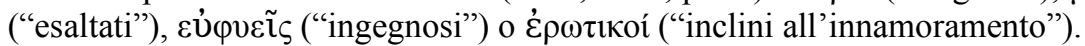

70 Sulla ripresa senecana dei passi platonici e aristotelici da dossografie, vd. F. MEWIS, De Senecae philosophi studiis litterarum. Dissertatio, p. 27; D'AGOSTINO, V., Seneca e il De tranquillitate animi, p. 65; CAVAlCA SCHIROLI, M. G. (a c. di.), Lucio Anneo Seneca, De tranquillitate animi, p. 139; SETAIOLI, A., Seneca e i greci ..., cit., p. 153.

71 CIC. Tusc. 1, 80, Vol. I, p. 101: Aristoteles quidem ait omnis ingeniosos malancholicos esse, ut ego me tardiorem esse non moleste feram. Enumerat multos, idque quasi connstet, rationem cur ita fiat adfert. 72 PLUTARCHUS (d'ora in poi, PLUT.), Lysander, 2, 3, p. 14.

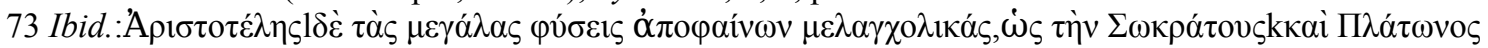

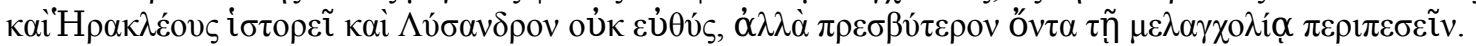
74 Questa ipotesi si fa strada, tra l'altro, nell'analisi condotta da Hall (HALL, J., Seneca as a source for earlier thought, p. 424). 
considerazione - discutibile ma di certo non erronea - dell'assenza di ratio come denominatore comune delle condotte elencate da Aristotele. Va precisato che, altrove (chiaramente in contesti nei quali essa non è applicata all' ingenium), Seneca qualifica in modo ben diverso la stessa capacità di staccarsi dai limiti della consuetudine e di travalicare quelli imposti dalla morale comune ${ }^{75}$.

Di sicuro, ad ogni modo, Schopenhauer sceglie anche questa volta una sententia senecana dalla notevole fortuna in età moderna, forse anche perché incarna alla perfezione il concetto romantico di "genio e sregolatezza". Nella letteratura inglese, dall'età elisabettiana in poi, è sia oggetto di esplicite citazioni (Ben Johnson la ricorda a proposito dell'ingenium che consente al poeta di schiudere il tesoro immaginifico custodito nella sua mente ${ }^{76}$ ) sia vere e proprie parafrasi poetiche (great wits are sure to madness near allied ${ }^{77}$ è un noto verso di Dryden). Con una leggera variazione (nullum unquam extitit magnum ingenium sine aliqua dementia ${ }^{78}$ ), sarà presente anche nel terzo dei Problemi di Kierkegaard, a proposito, appunto, del rapporto tra genio e dementia.

Nella visione schopenhaueriana, il concetto resta una dimensione assolutamente sterile - come si è ricordato finora - sia nell'ambito delle relazioni umane sia in quello artistico (includendo nel novero di quest'ultimo anche la poesia). C'è però un'altra sfera in cui il concetto mostra appieno la sua infruttuosità, ed è quella morale. Schopenhauer,

75 Un esempio lampante è offerto da ir. 1, 13, 3, p. 148, ove Seneca scrive ironicamente: isto modo dic et phrenesin atque insaniam viribus necessariam, quia saepe validiores furor reddit. Non può che destare qualche perplessità il fatto che anche in questo caso Seneca associ la follia all'ubriachezza, formulando però una valutazione di segno diametralmente opposto per entrambe, e soprattutto per la convinzione che, in modo occasionale, possano rendere gli uomini protervi e temerari (subito prima esorta infatti, sempre in tono ironico, a considerare utile la ebrietas proprio per questi motivi). Il Cordovese non fa che citare un principio topico che affonda le proprie radici nella lirica greca arcaica. Già in Bacchilide l'ebbrezza è in grado di risvegliare nella mente umana un'afrodisiaca speranza di energia, potenza e dominio (BACCHILIDES, Fragmenta, 27, 1 ss., p. 579). Anche secondo Platone essa può apportare fiducia nella riuscita di imprese diversamente non contemplate, poiché induce a varcare le soglie della razionalità e della convenzione, con una conseguente e proficua libertà di parole e pensieri ( $L g$. 649b, Vol. I, p. 37). Non ci si può esimere dal ricordare che Orazio, nella lettera a Torquato, associa anche lui come Seneca, nella cornice del banchetto, insania ed ebrietas, citando, tra gli effetti, la predisposizione alle arti (HORATIUS, Epistualae 1, 5, 13 ss., p. 73 [d'ora in poi, HOR. ep.]: potare et spargere flores / incipiam patiarque vel inconsultus haberi. / Quid non ebrietas dissignat? Operta recludit, / spes iubet esse ratas, ad proelia trudit inertem, /sollicitis animis onus eximit, addocet artis). Seneca sembra rievocare il principio oraziano sia nel passo citato da Schopenhauer sia nel De ira, ma per sostenerlo nel primo caso, per ribaltarlo nel secondo.

76 JOHNSON, B., Timber, or Discoveries, p. 586.

77 DRYDEN, J., Absalom and Architophel, v. 163, p. 172.

78 KIERKEGAARD, S., Problema terzo. Dal punto di vista etico si può scusare il silenzio di Abramo con Sara, Eliezer, Isacco sul suo progetto?, in ID., Timore e tremore - Aut-Aut (Diapsalmata), p. 138. 
a tal proposito, cita il principio senecano velle non discitur ${ }^{79}$, e lo fa in due occasioni, dai contesti contenutistici abbastanza simili, rispettivamente ai paragrafi $55^{80}$ e $66^{81}$. Nel primo caso, il filosofo di Danzica evidenzia l'impossibilità di agire sulle inclinazioni caratteriali dell'individuo attraverso il mezzo verbale, perché la volontà, che esula da condotte parziali ed episodiche per investire la sua essenza più intima, sfugge a ogni condizionamento esterno. La seconda ricorrenza ha la fuzione di supportare l'idea dell'incomunicabilità della virtù, che, in quanto realtà eterna e assoluta, non può essere razionalmente rappresentata e poi spiegata a parole: queste ultime potranno fornire semplici schemi comportamentali, tracciare un solco per orientare gli atti di volontà, ma non cambiare la volontà stessa nella sua natura intrinseca. Schopenhauer mette in risalto come il pensiero senecano si attesti su una linea diametralmente opposta rispetto a quella dei veterostoici, preferendo la verità al rispetto dei maestri, i quali asserivano che

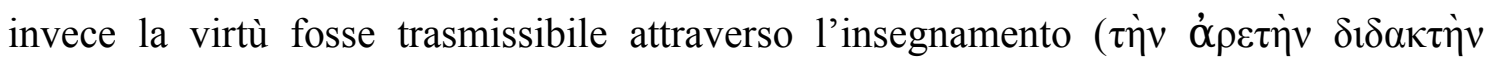
عìv $\alpha$, troviamo riportato al paragrafo 55$)^{82}$. Traslando il discorso della virtù da un piano prettamente filosofico a quello religioso, possiamo notare come la considerazione di Seneca citata da Schopenhauer precorra piuttosto l'ottica cristiana: la teologia morale di Sant'Agostino ridimensiona a più riprese le visioni intellettuali della virtù, scevre da quella Luce imperscrutabile che si identifica con Dio e che dà un senso di pienezza alle stesse realtà che un'anima schiava dei sensi carnali, pur nel pieno della sua facoltà razionale, può percepire solo parzialmente ${ }^{83}$. Come ricorda Giovanni Reale ${ }^{84}$, Seneca demolisce l'intellettualismo greco che vede nella voluntas un mero prodotto del pensiero (limite di cui - come si è visto - lo stesso Schopenhauer dà conto), e alla tradizionale distinzione stoica tra saggi e stolti aggiunge quella tra buona e cattiva volontà $^{85}$, rivendicando la validità della propria scelta: huius rei conscius mihi sum: volo et mente tota volo ${ }^{86}$.

79 SEN. ep. 81, 13, Vol. I, p. 267.

80 SCHOPENHAUER, A., Il mondo ..., cit., Vol. I, § 55, cit., p. 541.

81 Ibid., § 66, p. 646.

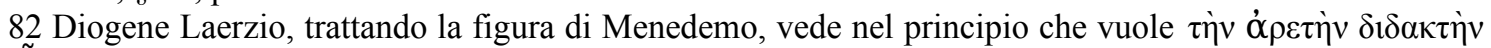
Ẽ் $v a l$ un forte punto di convergenza tra la scuola stoica e quella cinica (DIOG. LAERT. 6, 105, p. 443).

83 Cfr. AUGUSTINUS, A. (d'ora in poi, AUG.), Sermones de Scripturis, 113, 3, 5, p. 663; de Genesi ad litteram 12, 31, 59, p. 479.

84 REALE, G., I problemi del pensiero antico. Le scuole ellenistico-romane, pp. $356 \mathrm{~s}$.

85 Su questi aspetti, vd. anche POHLENZ, M., La Stoa, Vol. II, pp. 89 s.

86 SEN. ep. 71, 36, Vol. I, p. 217. 
Sempre nel paragrafo 55, Schopenhauer analizza le dinamiche del dolore umano, per dimostrare come esso non derivi tanto da una contingenza materiale, ma dai pensieri, che si affastellano nella mente soggiogandola e affollandola di inquietudini tali da rendere sostenibilissima, al confronto, ogni forma di patimento fisico. Non è un caso che gli individui dialaniati dal dolore morale si strappino i capelli, si percuotano il petto o si graffino il viso: sono tutte inconsapevoli strategie di distrazione. Né tantomeno è un caso che a instillare l'idea del suicidio siano sempre dolori dell'anima, e mai del corpo, né che quest'ultimo risenta in modo logorante delle paure e degli affanni prodotti da un pensiero che non conosce requie ${ }^{87}$. È qui che il filosofo del Mondo, per dimostrare come spesso il timore della sofferenza sia più gravoso della sofferenza stessa, ricorda il principio senecano per cui plura sunt, quae nos terrent, quam quae premunt, et saepius opinione quam re laboramus ${ }^{88}$. Queste parole non possono che destare nel lettore moderno una certa suggestione, perché, insieme ad altri passi delle Lettere in cui Seneca insiste sullo stesso concetto e su altri simili, vanno a confluire in una sorta di testamento spirituale che raccoglie pensieri definitivi, propri di un uomo che in cuor suo avverte l'implacabile incedere di una fine violenta, strappata al naturale evolversi della sua esistenza: "non ci tormenta tanto il dolore, quanto l'idea che ne abbiamo", "calibra la tua paura: capirai che ciò che temi o è poco rilevante, o è di breve durata" ${ }^{89}$ sono moniti che il Cordovese sembra rivolgere a se stesso prima ancora che al suo discepolo, quasi per esorcizzare quei cupi sentori alimentati dalla malcelata avversione di Tigellino e dalla folle e plagiabile volubilità del princeps, ancor più avvalorati dall'allontanamento e dalla morte misteriosa di Afranio Burro.

La dimensione prettamente intima di questa sezione lascia il posto, pochi paragrafi più avanti, a quella collettiva, e Schopenhauer, con una programmatica destrutturazione delle idee kantiane, si addentra nella filosofia del diritto più pura e dopo una lunga parentesi sulla proprietà - sceglie di affrontare l'annosa questione del rapporto tra colpa e pena. Il suo orientamento, che si attesta su un valore di detterente della pena, è dichiaratemente platonico, e coinvolge altresì la visione senecana per cui nemo prudens punit quia peccatum est, sed ne peccetur (asserto che il filosofo di 87 Cfr. SCHOPENHAUER, A., Il mondo ..., cit., Vol. I, § 55, p. 548. 88 SEN. ep. 13, 4, Vol. I, p. 30.

89 SEN. const. sap. 5, 2, p. 76: ut ... non dolore tantum, sed doloris opinione vexemur; ep. 24, 2: timorem tuum taxa: intelleges profecto aut non magnum aut non longum esse quod metuis. 
Danzica colloca nel sedicesimo capitolo del primo libro del De ira ma che in realtà figura nel diciannovesimo ${ }^{90}$ ). Soprattutto nel De ira (ma anche altrove) ${ }^{91}$, Seneca ha modo di esprimersi a più riprese sull'importanza della misura nella punizione e sulla sua profonda valenza pedagogica, richiamando anch'egli, in modo palese, la posizione di Platone, il quale, nel passo delle Leggi citato in questa sede da Schopenhauer ${ }^{92}$, specifica che persino la più severa delle pene non deve esser comminata contro il misfatto in sé, ma in funzione di un maturo e consapevole ravvedimento del malattore e di una crescita morale della comunità intera. Il punto di convergenza più forte tra la visione schopenhaueriana espressa nel paragrafo e tutte le fonti antiche chiamate in causa è però l'individuazione della ratio della pena nell'aspetto precauzionale, prima ancora che rieducativo. Proprio per questo motivo, le stesse parole mutuate da Seneca rimandano più all'altro passo platonico cui Schopenhauer fa riferimento, quello tratto dal Protagora ${ }^{93}$, nel quale il filosofo ateniese si schiera contro ogni forma di giustizia retributiva, evidenziando come chiunque voglia vendicare un'ingiustizia agisca in maniera irrazionale - quasi ferina - nell'assurdo tentativo di annullare il passato senza proiettarsi nel futuro. Oltretutto - aspetto questo che fa acquistare ancor più efficacia all'affermazione e al contempo rende inequivocabile il modello di riferimento - il Cordovese duplica in un'antitesi il verbo peccare mantenendo la figura etimologica (peccare / peccetur), proprio come fa Platone nel Protagora col corrispettivo ${\underline{\alpha} \delta 1 \kappa \varepsilon \tilde{\imath} v^{94}}^{\text {; }}$ vale poi la pena segnalare la doppia opposizione, nel testo platonico, tra $\tau 1 \mu \omega \rho i ́ \alpha-1 a$ vendetta menzionata subito dopo e alimentata dalla stessa irrazionalità di cui si

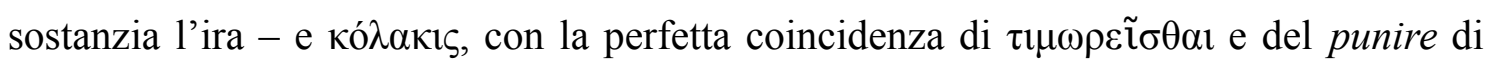
Seneca.

90 SEN. ir. 1, 19, 7, p 164. Su questo passo, vd. MUSIO, A. (a c. di), Lucio Anneo Seneca..., cit., p. 254 s. 91 Cfr. SEN. ir. 1, 15, 1, p. 150: corrigendus est itaque qui peccat et admonitione et vi, et molliter et aspere, meliorque tam sibi quam aliis faciendus non sine castigatione, sed sine ira; ibid., 3, p. 151: nil minus quam irasci punientem decet, cum eo magis ad emendationem poena proficiat, si iudicio lata est; ibid., 16, 2, p. 152: omne poenae genus remedi loco admoveo; clem. 1, 16, 3, p. 29: nonne pessimus pater videbitur, qui adsiduis plagis liberos etiam ex levissimis causis compescet? Uter autem praeceptor liberalibus studiis dignior, qui excarnificabit discipulos, si memoria illis non constiterit aut si parum agilis in legendo oculus haeserit, an qui monitionibus et verecundia emendare ac docere malit? Tribunum centurionemque da saevum: desertores faciet, quibus tamen ignoscitur.

92 PLAT. Lg. 934a s., Vol. IV, p. 40 s.

93 PLAT. Protagoras, 324a s., p. 38 s.

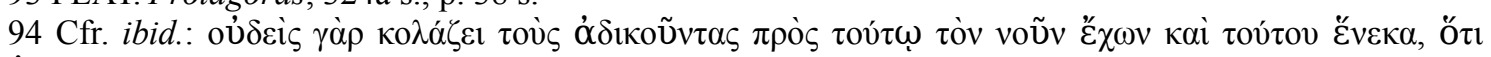

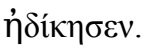


Un modello impeccabile del discorso schopenhaueriano è costituito dal passo del Gorgia, di sicuro il più compendioso fra quelli ricordati dal filosofo di Danzica ${ }^{95}$ : vi si riepiloga brillantemente il duplice ruolo della pena, quello di mettere il colpevole nella condizione di non commettere altri crimini e di fornire un monito lampante agli altri cittadini. Il passo sarà poi ripreso dallo stesso Seneca in un'altra sua riflessione sull'esercizio della giustizia, sempre mosso da finalità sia rieducative sia preventive, all'interno del De clementia ${ }^{96}$.

Il secondo volume del Mondo reca come epigrafe un pensiero senecano che riconduce a un discorso già affrontato nella Vorrede alla seconda edizione della Quadruplice radice: l'argomento in questione è quello della gloria, che il Cordovese tratta, come si è rilevato, in ep. 79,17 , e la citazione in questo caso è paucis natus est qui populum aetatis suae cogitat ${ }^{97}$. Si tratta di parole che precedono di poco quelle riportate nella prima opera di Schopenhauer (etiam si omnibus tecum viventibus silentium livor indixerit, venient qui sine offensa, sine gratia iudicent), e se in quella sede si considerava la proiezione senecana nel futuro, con l'importanza accordata alla buona fama presso i posteri, qui si evidenzia il rapporto col presente e il contemptus per l'apprezzamento dei contemporanei: il sapiens non può sperare in una ricompensa per i suoi preziosi insegnamenti finché è ancora in vita, e Seneca giunge perciò alla conclusione di potersi davvero rivolgere alle moltitudini di domani solo sottraendosi alla vista, all'attenzione e al giudizio dei pauci dei suoi giorni. Questa idea del secessus dal populus aetatis suae è espressa diffusamente nel De otio $^{98}$, ma anche in altre lettere,

95 PLAT. Gorgias, 525b, p. 221.

96 SEN. clem. 1, 22, 1 s., p. 37 s.: transeamus ad alienas iniurias, in quibus vindicandis haec tria lex secuta est, quae princeps quoque sequi debet: aut ut eum, quem punit, emendet, aut ut poena eius ceteros meliores reddat, aut ut sublatis malis securiores ceteri vivant. Ipsos facilius emendabis minore poena ; diligentius enim vivit, cui aliquid integri superest. Nemo dignitati perditae parcit; impunitatis genus est iam non habere poenae locum. Civitatis autem mores magis corrigit parcitas animadversionum; facit enim consuetudinem peccandi multitudo peccantium, et minus gravis nota est, quam turba damnationum levat, et severitas, quod maximum remedium habet, adsiduitate amittit auctoritatem.

97 SEN. ep. 79, 17, Vol. I, p. 260.

98 Cfr. SEN. ot. 6, 4, p. 174: quo animo ad otium sapiens secedit? ut sciat se tum quoque ea acturum per quae posteris prosit. Nos certe sumus qui dicimus et Zenonem et Chrysippum maiora egisse quam si duxissent exercitus, gessissent honores, leges tulissent; quas non uni ciuitati, sed toti humano generi tulerunt. Quid est ergo quare tale otium non conueniat uiro bono, per quod futura saecula ordinet nec apud paucos contionetur sed apud omnis omnium gentium homines, quique sunt quique erunt? 
al cui interno emerge la pluralità delle dimensioni interessate dal secessus stesso, che riguarda sia le persone, sia la vita pubblica, sia la propria carriera ${ }^{99}$.

Entrando nel vivo del secondo volume del Mondo, un punto fondamentale della gnoseologia schopenhaueriana è la vacuità delle sensazioni impresse esternamente dalle cose e degli stati d'animo che ne derivano, per cui le une e gli altri non possono assolutamente confluire nel bagaglio esperienziale che andrà a veicolare, con i suoi insegnamenti, le azioni dell'individuo: se già le impressioni sono deboli, lo sono ancor di più le loro immagini sensoriali, soggette all'azione inesorabile del tempo, che le sbiadisce di giorno in giorno sino al definitivo dissolvimento ${ }^{100}$. L'unico depositario possibile degli insegnamenti procurati dall'esperienza, perché svincolato dall'opera logorante del tempo e dall'inganno delle impressioni e delle loro immagini, è il concetto, di cui si è già evidenziato lo strettissimo legame con la ragione. Proprio per questo motivo, Schopenhauer si appella alla massima senecana si vis tibi omnia subicere, te subice rationi ${ }^{101}$, che ricorre anche diversi capitoli più avanti a proposito della necessità di affidarsi alla facoltà razionale per le scelte di natura pratica, in virtù della lettura sistemica della dimensione morale che essa offre ${ }^{102}$. La vaga coloritura gnoseologica di questo adattamento del discorso senecano, ovviamente, ha ben poca attinenza col contesto d'origine, improntato sul principio del controllo degli adfectus, che, in un passo contenutisticamente molto affine a quello citato, il Cordovese giudica tanto cattivi servitori quanto cattivi comandanti ${ }^{103}$.

Nello stesso capitolo, poco oltre, due passi senecani sono citati consecutivamente all'interno di un elenco di sentenze di autori greci e latini volto a dimostrare come tutti i sistemi filosofici dell'antichità, eccettuato quello platonico, fossero accomunati da una morale marcatamente eudaimonistica ${ }^{104}$. Il primo passo è tratto da una lunga epistola quasi del tutto dedicata alla confutazione del pensiero 99 Cfr. SEN. ep. 8,2, Vol. I, p. 14: secessi non tantum ab hominibus sed a rebus, et in primis a meis rebus; ep. 14, 14, Vol. I, p. 37: sed postea videbimus an sapienti opera rei publicae danda sit: interim ad hos te Stoicos voco qui a re publica exclusi secesserunt ad colendam vitam et humano generi iura condenda sine ulla potentioris offensa;

100 Cfr. SCHOPENHAUER, A., Il mondo ..., cit., Vol. II, cap. 6: Sulla dottrina della conoscenza astratta o della ragione, p. 93.

101 SEN. ep. 37, 4, Vol. I, p. 101.

102 Cfr. SCHOPENHAUER, A., Il mondo ... , cit., Vol. II, cap. 16: Sull'uso pratico della ragione e sullo stoicismo, p. 215.

103 Cfr. SEN. ir. 1, 9, 4, p. 140.

104 SCHOPENHAUER, A., Il mondo ..., cit., Vol. II, cap. 16: Sull'uso pratico della ragione e sullo stoicismo, p. 218. 
posidoniano con riguardo al ruolo della sapientia, che il filosofo di Apamea svilirebbe fino ad attribuirle l'origine di tutte le attività pratiche della storia dell'uomo, senza realizzare come essa costituisca invero l'unico tramite incontrovertibile per raggiungere la felicità in questa vita (ceterum [sapientia] ad beatum statum tendit, illo ducit, illo vias aperit $\left.{ }^{105}\right)$. Il secondo passo campeggia nella lettera che Seneca impernia sugli insegamenti dei suoi maestri, al cui interno, dopo aver operato uno scrupoloso distinguo tra gli approcci metodologici di philologi, grammatici e philosophi, assegna all'ascolto e alla lettura di questi ultimi la prerogativa di educare le menti al conseguimento della beatitudine (illud admoneo, auditionem philosophorum, lectionemque, ad propositum beatae vitae trahendum $\left.{ }^{106}\right)$.

Sempre in seno allo stesso orientamento eudaimonistico, la filosofia cinica si attesta su una posizione decisamente eccentrica, che vede nei beni materiali una fonte di angosce inesauribili per l'animo umano, teso prima alla loro conquista, poi al loro mantenimento, tormentato dalla paura della loro perdita e dalla disperazione qualora questa si verifichi: il risultato è un carico di sofferenze che supera in misura impressionante quelle generate dalla mancanza dei beni stessi, per cui l'unica soluzione auspicabile è la rincuncia alla ricchezza ${ }^{107}$. Schopenhauer si affida all'efficace resoconto dello spirito cinico offerto da Seneca nel De tranquillitate animi, operandone a sua volta una selezione: cogitandum est quanto levior dolor sit non habere quam perdere, et intellegemus paupertati eo minorem tormentorum quo minorem damnorum esse materiam. - - - Tolerabilius autem est, ut dixi, faciliusque non adquirere quam amittere. - - - Diogenes effecit, ne quid sibi eripi posset, - - - qui se fortuitis omnibus exuit. - - Videtur mihi dixisse: age tuum negotium, fortuna: nihil apud Diogenen iam tuum est ${ }^{108}$. La cifra stilistica di questo passo è senza dubbio costituita dall'antitesi, che oppone prima non habere e perdere, poi non adquirere e amittere, a evidenziare col maggior vigore possibile la contrapposizione tra la vita tranquilla di chi nulla ha e nulla guadagna a quella travagliata di chi, avendo troppo, è destinato a perdere e impoverirsi (e, dunque, angustiarsi). Lo stesso contrasto, che Seneca non manca di rimarcare in

105 SEN. ep. 90, 27, Vol. II, p. 340.

106 SEN. ep. 108, 35, Vol. II, p. 459.

107 Cfr. SCHOPENHAUER, A., Il mondo ... , cit., Vol. II, cap. 16: Sull'uso pratico della ragione e sullo stoicismo, p. 218.

108 SEN. tr. an. 8, 2; 3; 4; 5; 7, pp. 212 ss. Da segnalare che gli editori successivi al Ruhkopf emendano concordemente iam tuum in iam tui. 
forma più $\mathrm{o}$ meno attenuata anche in altre sedi ${ }^{109}$, è suggerito dall'invito oraziano, rivolto all'amico Fusco, a non crearsi dipendenze materiali, a evitare i lussi, e a riflettere su come un'umile dimora possa ospitare vite ben più felici di quelle dei sovrani e dei ricchi in generale ${ }^{110}$. È proprio Orazio, del resto, l'autore della sprezzante esclamazione divitias miseras! ${ }^{111}$, ripresa poi da Seneca in un'altrettanto efficace qualificazione dei miserrimi divites ${ }^{112}$. Tornando al testo citato da Schopenhauer, non è casuale, in riferimento alle ricchezze, la scelta del verbo exuere, impiegato nell'epistolario senecano a proposito dell'azione della morte che ci libera dal corpo, il quale, con la sensibilità della sua natura materiale, veicola anche la sofferenza ${ }^{113}$ : l'idea di una spoliazione benevola, fortunata mantiene la sua assoluta adeguatezza.

Quello appena trattato è un punto d'incontro tra pensiero cinico e stoico che prepara il lettore alla considerazione schopenhaueriana del secondo come una sorta di costola staccatasi dal primo. Caratteristica - e secondo Schopenhauer, in qualche modo, anche difetto - degli stoici è di aver trasformato l'insegnamento pratico dei cinici in pura teoresi: il risultato è una dottrina morale per certi versi mancante di pragmatismo, di un reale contatto con la realtà, che certo non avrebbe visto come attuabile l'idea di poter annichilire, in nome della $\alpha \dot{\alpha} \alpha \dot{\theta} \theta \varepsilon 1 \alpha$, il desiderio di comodità già sperimentate, il bisogno che ne deriva e la frustrazione per la loro perdita. Dal punto di vista del filosofo del Mondo, gli stoici risolverebbero questa contraddizione con l'atteggiamento vagamente ipocrita di chi millanta noncuranza - o addirittura fastidio - dei beni nel momento stesso in cui ne usufruisce: dunque, pura esteriorità, come evidenzia il pungente paragone con benedettini e agostiniani, che starebbero ai francescani e ai cappuccini proprio come gli stoici ai cinici ${ }^{114}$.

Che si concordi o meno col giudizio di Schopenhauer, non si può non riconoscergli il merito di aver centrato ed enucleato in pochissime parole la chiave di volta del pensiero stoico in tutta la sua storia evolutiva: la realizzazione dell'assoluta

109 Cfr. ad es. const. sap. 13, 3, p. 98: scit enim illos (scil. divites) nihil a mendicis differre, immo miseriores esse; ер. 115, 16, Vol. II, p. 492: maiore tormento pecunia possidetur quam quaeritur.

110 Cfr. HOR. ep. 1, 10, 31 ss., p. 82: si quid mirabere, pones / invitus. Fuge magna; licet sub paupere tecto / reges, et regum vita praecurrere amicos.

111 HOR., Sermones (d'ora in poi, serm.), 2, 8, 18, p. 210.

112 SEN. ep. 94, 7, Vol. II, p. 365: efficias oportet ut sciat (scli. avarus) pecuniam nec bonum nec malum esse; ostendas illi miserrimos divites.

113 Cfr. SEN. ep. 24, 18, Vol. I, p. 70: mors nos aut consumit aut exuit.

114 Cfr. SCHOPENHAUER, A., Il mondo ... , cit., Vol. II, cap. 16: Sull'uso pratico della ragione e sullo stoicismo, p. 223. 
indipendenza del corso del mondo dalla nostra volontà, attraverso l'impiego della ratio che consente di comprendere ed accettare la labilità di tutti i beni che si avvicendano tra le mani dell'uomo. In tal senso vanno lette le parole senecane, citate in questa sede, $s i$ quid humanarum rerum varietas possit, cogitaverit, ante quam senserit ${ }^{115}$, non tanto come l'invito all'angosciosa attesa di un futuro imponderabile pronto a spodestare $\mathrm{i}$ momenti di benessere dal corso della vita umana, ma piuttosto come la serena accettazione sia della prospettiva di un'eventuale perdita, sia dell'idea della sostanziale vacuità dei beni perduti.

Nella stessa ottica, con un sottile richiamo alla posizione cinica precedentemente analizzata, si inquadra la sentenza senecana, riportata a poca distanza, che equipara il non desiderare all'avere, in considerazione del loro identico effetto, vale a dire l'assenza di turbamenti: nihil interest utrum non desideres an habeas. Summa rei in utroque est eadem: non torqueberis ${ }^{116}$.

Due altri passi senecani sono citati consecutivamente subito dopo, il primo come

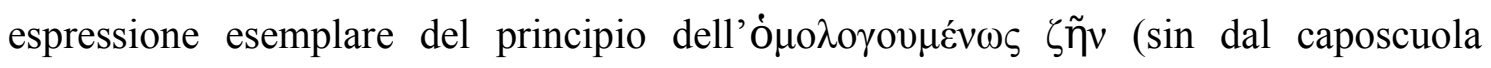
Zenone - d'accordo con Cleante, Posidonio e Crisippo - il solo e unico $\tau \dot{\lambda} \lambda o \varsigma$ dell'esistenza umana coincidente con la virtù ${ }^{117}$ ), il secondo come sintesi ideale dello spirito stoico nella sua globalità.

La frase perfecta virtus est aequalitas et tenor vitae per omnia consonans sibi è estrapolata dal periodo in cui si inscrive e sottoposta a una libera variazione rispetto al testo originale, in base al quale la costanza e la coerenza del comportamento sono accessorie alla perfezione della virtù, e non a questa direttamente assimilate (hoc et illud accedat, ut perfecta virtus sit, aequalitas ac tenor vitae per omnia consonans $\left.s i b i^{118}\right)$. In realtà, la spiegazione della teleologia stoica della natura è già offerta da Cicerone in modo non meno lineare e pertinente sia nel De finibus sia nel De officiis ${ }^{119}$.

115 SEN. ep. 98, 5, Vol. II, p. 407.

116 SEN. ep. 119, 2, Vol. II, p. 507.

117 Cfr. DIOG. LAERT. 7, 87, p. 496.

118 SEN ep. 31, 8, Vol. I, p. 91.

119 CIC. fin. 2, 34, p. 49: Stoicis (finis bonorum est) consentire naturae, quod esse volunt e virtute, id est, honeste vivere; quod ita interpretantur, vivere cum intelligentia rerum earum, quae natura evenirent; off. 3, 13, pp. 82 s.: quod summum bonum a Stoicis dicitur, convenienter naturae vivere, id habet hanc, ut opinor, sententiam, cum virtute congruere semper, cetera autem, quae secundum naturam essent, ita legere, si ea virtuti non repugnarent. 
Maggiormente degna di nota, nella sua icastica brevitas, è forse l'altra definizione senecana riportata da Schopenhauer, quella relativa alla felicità: quid est beata vita? securitas et perpetua tranquillitas. Hanc dabit animi magnitudo, dabit constantia bene iudicati tenax ${ }^{120}$. Il motivo della sua rilevanza è duplice. Da una parte, infatti, essa esprime in modo tanto conciso quanto puntuale la prospettiva stoica, poiché focalizza l'attenzione sul doppio filo che lega la beata vita alla virtù in un rapporto paritetico $^{121}$, alla constantia in uno di dipendenza causale ${ }^{122}$. Dall'altra parte, la definizione senecana supera addirittura l'arroccamento intellettualistico tipicamente stoico, riportando il discorso su un piano pragmatico e comportamentale, forse anche in virtù del momento particolare della vita del Cordovese in cui le circostanze lo conducono fuori da un contesto politico ormai proibitivo: illuminare per sé - prima ancora che per gli altri - il cammino verso la felicità diventa l'unica strategia possibile per la sopravvivenza di una dimensione morale altrimenti anestetizzata in una sterile segregazione $^{123}$. Securitas e tranquillitas ${ }^{124}$ sono anche le parole che, secondo Cicerone, traducono al meglio il principio democriteo dell' $\varepsilon \dot{U} \theta v \mu$ í $^{125}$, ma è lo stesso Seneca, all'inizio del De tranquillitate, a chiarire la sua posizione al riguardo, precisando la sua ammirazione per Democrito e per il concetto da lui espresso, ma rivendicando la scelta di farlo proprio e di esprimerlo, appunto, attraverso la nozione di tranquillitas $^{126}$. A cimentarsi nella ricerca di una definizione appropriata per la felicità secondo la visione stoica è poi Epitteto, che da Seneca non si discosta molto, chiamando in causa tò

120 SEN. ep. 92, 3, Vol. II, p. 351.

121 Per Seneca, tranquillità e continuità nel tempo sono proprio le caratteristiche della gioia arrecata dalla virtù (cfr. ep. 27, 3, Vol. I, p. 77: sola virtus praestat gaudium perpetuum, securum).

122 Risulteranno esplicative, al riguardo, le parole di Scarpat riferite proprio a questa definizione senecana: "La constantia non è il risultato della securitas e non è nemmeno la securitas stessa (...), essa viene prima della securitas, essa procura la securitas" (SCARPAT, G., Parrhesia greca, parrhesia cristiana, p. 146).

123 Scrive giustamente Grilli, in riferimento allo stesso passo senecano: "Egli (scil. Seneca), uscito dalle tempeste della vita, è giunto al $\lambda \iota \eta \eta ́ v$, dove la vita si conduce serena e tranquilla con il conforto della lettura e della meditazione" (GRILLI, A., Il problema della vita contemplativa nel mondo greco-romano, p. 279).

124 I due termini tornano a essere abbinati da Seneca in ep. 95, 12, Vol. II, p. 384: decreta sunt quae muniant, quae securitatem nostram tranquillitatemque tueantur, quae totam vitam totamque rerum naturam simul contineant.

125 Cfr. CIC. fin. 5, 23, p. 166.

126 Cfr. SEN. tr. an. 2, 3, p. 193. Tranquilla quies (Hercules furens, 160, p. 7), quies tranquilla (Troades, 994 s., p. 73) resteranno i più remoti e sospirati aneliti dei personaggi tragici senecani. 


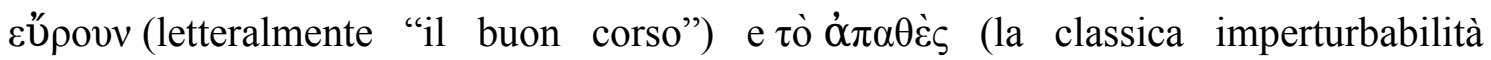
stoica $)^{127}$.

Il capitolo si chiude con un rapido cenno al panteismo stoico, e Schopenhauer, pur non soffermandosi in spiegazioni di sorta, si affida ancora una volta a quella che giudica un'encomiabile sintesi senecana: quid est Deus? Mens universi. Quid est Deus? Quod vides totum, et quod non vides totum. Sic demum magnitudo sua illi redditur, qua nihil maius excogitari potest, sic solus est omnia, opus suum et extra et intra tenet ${ }^{128}$. Dal testo citato appare chiaro come il filosofo del Mondo voglia appuntare l'attenzione del lettore su due tratti distintivi e tra loro complementari dell'idea stoica della divinità, vale a dire l'inesistenza di qualunque realtà pensabile che non si possa identificare direttamente con la divinità stessa, o comunque con una sua manifestazione, e la sostanziale corrispondenza tra il Dio e il mondo: si tratta di denominatori comuni a ogni fase del pensiero stoico, da Crisippo ${ }^{129}$ a Cleante ${ }^{130}$, da Filodemo ${ }^{131}$ a Cicerone ${ }^{132}$, per arrivare, ovviamente, al Cordovese. La sua indagine alla ricerca del divino prosegue nel secondo libro delle Naturales quaestiones, ove giunge a definirlo rector custosque universi, animus ac spiritus mundi, operis huius dominus et artifex, cui nomen omne convenit. Dopodiché, passa in rassegna tutte le altre denominazioni possibili, tutte ugualmente pertinenti: lo si può chiamare "fato" in quanto causa causarum, unico motore delle sorti dei viventi; lo si può chiamare "provvidenza", visto che di fatto provvede (providetur) al mondo, affinché tutto proceda linearmente, secondo il giusto ordine; può esser qualificato come "natura", perché origine di tutte le cose, vivificate dal suo soffio; tornando alla finitio della citazione, lo si può infine chiamare, semplicemente, "mondo", e non si rischia l'errore: ipso enim est hoc quod uides totum, partibus suis inditus, et se sustinens et sua ${ }^{133}$. Nel De beneficiis, Seneca esprime la stessa idea in modo più stringato, ma forse ancor più incisivo: quaecumque voles, illi nomina proprie aptabis vim aliquam effectumque coelestium rerum continentia ${ }^{134}$.

127 EPICTETUS, Dissertationes, 1, 4, 1, p. 17.

128 SEN., Naturales quaestiones (d'ora in poi, nat.), 1 praef. 13, p. 16.

129 Cfr. PLUT. De communibus notitiis, $1077 \mathrm{~d}$, p. 99.

130 Cfr. CIC., De natura deorum (d'ora in poi, nat. deor.), 1, 37, p. 16.

131 Cfr. PHILODEMUS (d'ora in poi, PHILOD.), De pietate, col. 5, pp. $114 \mathrm{~s}$.

$132 \mathrm{Nel}$ De natura deorum, Cicerone prima precisa che la divinità, ossia il mondo, è la sede di una ratio scevra da qualsivoglia imperfezione o contraddizione (cfr. nat. deor. 2, 34, p. 61), poi attribuisce al mondo, quo nihil fieri eccellentius potest, un'anima e un'entità divina giudicante (ibid. 45, p. 66).

133 SEN. nat. 2, 45, 1 ss., p. 146.

134 SEN., ben. 4, 7, 2, p. 91. 
Curiosamente, la citazione successiva è tratta da un passo nel quale il Cordovese chiama in causa proprio il dio degli stoici, anche se il tono è ben diverso. Il riferimento verte sulla caratteristica, sinora ben evidenziata, dell'incorporeità, espressa attraverso i tratti lapalissiani - fin troppo elementari e prosaici per i contesti filosofici poc'anzi analizzati - dell'assenza del cuore e della testa: Seneca se ne serve per una similitudine col bersaglio della sua sferzante satira, l'imperatore Claudio che, a guisa dello Stoicus deus, nec cor nec caput habet ${ }^{135}$. Diverso è il tono nell'Apokolokyntosis, diversissimo è il contenuto nel diciannovesimo capitolo del Mondo, incentrato sulla nevralgica contrapposizione tra volontà e intelletto, che Schopenhauer sceglie di spiegare, dopo una breve trattazione teorica, con una serie di esempi concreti alla portata di qualunque osservatore. Uno di questi è la distinzione terminologica, adottata da tutte le lingue, tra cuore e testa, elementi di una dicotomia che, nell'ottica schopenhaueriana, incarna alla perfezione quella alla base del capitolo (l'intelletto non è semplicemente assimilato alla testa, ma addirittura dichiarato "identico"136). La qualificazione senecana di Claudio, ironicamente accostato a una divinità perché privo sia di cuore sia di testa, si presta dunque ottimamente allo scopo.

Verso la definitiva conclusione dell'opera, il pessimismo di Schopenhauer e lo stoicismo del Cordovese si intersecano nella loro forma più autentica. Anche l'epistolario senecano volge al termine e, fatta ormai propria, da parte di entrambi, la consapevolezza di un ineludibile destino di morte e della precarietà di tutto ciò che è umano, accettata l'idea di una felicità che, nei fatti, non è che intellettuale forma di controllo dell'infelicità, non resta che suggerire a chi ambisce alla saggezza il metro per valutare i propri progressi: bonum tunc habebis tuum, cum intelleges infelicissimos esse felices $^{137}$. Così, per il filosofo di Danzica, non siamo nati per essere felici: è la salda verità che risuona, come un gelido epitaffio, nelle ultime pagine. Né riconoscerla, accettarla, condividerla renderà l'uomo felice, ma riconcilierà la sua vita col mondo, in un'armonia, in un equilibrio che è il fine ultimo della sua stessa esistenza ${ }^{138}$. E questo mondo, ben lungi dal configurarsi come campo d'azione di una natura deificata dagli

135 SEN., Apocolocyntosis, 8, 1, p. 80.

136 SCHOPENHAUER, A., Il mondo ... , cit., Vol. II, cap. 19: Del primato della volontà nell'autocoscienza, p. 336.

137 SEN. ep. 124, 24, Vol. II, p. 536.

138 SCHOPENHAUER, A., Il mondo ... , cit., Vol. II, cap. 49: L'ordine della salvezza, pp. 890 ss. 
stoici - rispetto ai quali si sono pur visti diversi punti di convergenza col pensiero schopenhaueriano - è in realtà "il peggiore di tutti i mondi possibili. (...) Basterebbe che fosse solo un po' peggiore, e non potrebbe più esistere" ${ }^{139}$ : è questo l'asse portante di un ateismo "scientifico", “onesto", "assoluto" - un ateismo che diventa pandemonismo così come Nietzsche, enucleando l'anima fortemente europea del filosofo del Mondo, ha modo di qualificarlo ${ }^{140}$.

\section{§ 3: Sulla volontà nella natura}

Nel paragrafo del saggio Sulla volontà della natura dedicato alla Linguistica, Schopenhauer evidenzia come il linguaggio, estrinsecazione immediata del pensiero umano e garante dell'intelligibilità del reale, sin dall'antichità abbia già ampiamente raggiunto quella pertinenza e profondità concettuale atta a svolgere in modo preciso e compiuto un ruolo così complesso ${ }^{141}$. Ancora una volta, egli chiama in causa, come già in precedenza nel Mondo, l'epistola senecana sulla volontarietà del beneficio e sulla riconoscenza a questo connaturata, in cui, riflettendo sulla semantica stessa del beneficium, il Cordovese scrive: mira in quibusdam rebus verborum proprietas est, et consuetudo sermonis antiqui quaedam efficacissimis et officia docentibus notis signat ${ }^{142}$.

Dopo il ricorso all'auctoritas senecana per legittimare la trattazione della volontà intrinseca che caratterizza anche quei corpi privi di conoscenza, percezione e pensiero, Schopenhauer riporta una serie di exempla, mutuati sia dalle lingue antiche sia da quelle moderne, a dimostrazione di come, all'interno dei loro sistemi, il lessico esprima appieno il concetto enunciato ${ }^{143}$. Il primo exemplum è proprio senecano, e ripropone un passo delle Naturales quaestiones nel quale si spiega l'anomalia del fenomeno del fulmine rispetto agli altri fuochi, la cui direzione procede di norma dall'alto verso il basso. Il fulmine è paragonato alla chioma di quegli alberi costretti a guardare il terreno ma che, una volta liberati e assecondati nel loro orientamento spontaneo, tornano istantaneamente al loro posto: in his, ignibus accidit, quod

139 Si tratta di un pensiero esternato da Schopenhuer a Frédéric Morin, in un colloquio del marzo 1858 (SCHOPENHAUER, A., Gespräche, pp. 331 ss.).

140 NIETZSCHE, F., La gaia scienza, § 357, p. 268.

141 Cfr. SCHOPENHAUER, A., Sulla volontà della natura, p. 163.

142 SEN. ep. 81, 9, Vol. I, p. 266.

143 Cfr. SCHOPENHAUER, A., Sulla volontà ..., cit., pp. 163 s. 
arboribus: quarum cacumina, si tenera sunt, ita deorsum trahi possunt, ut etiam terram attingant; sed quum permiseris, in locum suum exsilient ${ }^{144}$. Da qui la conclusione, dominata da una decisa preponderanza del campo etimologico della volontà: itaque non est quod eum spectes cuiusque rei habitum, qui illi non ex voluntate est. Si ignem permittis ire quo velit, caelum repetet ${ }^{145}$. Le chiome verdi, nel momento in cui è loro consentito, ritornano nella propria posizione; il fuoco, se segue il suo volere, si indirizza verso l'alto; non resta che considerare, a fronte di questa energia volitiva che tutto permea e tutto muove, l'assoluta inutilità di trattare gli aspetti delle cose non conformi alla loro voluntas. Quello di Seneca, per quanto eloquente, è l'unico exemplum che Schopenhauer estrapola dalla tradizione latina, seguito solo da una frase di Plinio che svolge quasi la funzione di corollario al pensiero senecano, perché, come il filosofo stesso specifica, ne costituisce una sintetica generalizzazione (nec quaerenda in ulla parte naturae ratio, sed voluntas $\left.{ }^{146}\right)$. Dopodiché, si apre l'elenco degli esempi tratti dalla letteratura greca, quattro in tutto, di cui tre passi aristotelici ${ }^{147}$ e uno costituito da tre versi di Anacreonte ${ }^{148}$ : se lo Stagirita insiste, sia semanticamente sia

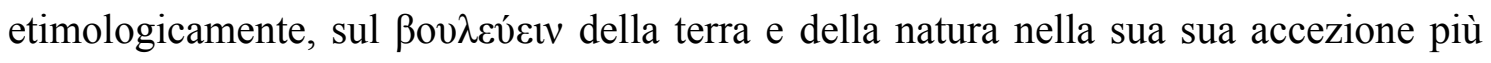
ampia e totalizzante, il lirico descrive i riccioli della sua amata che cascano scomposti $\dot{\omega} \varsigma, \theta \dot{\varepsilon} \lambda \omega \sigma \mathrm{l}$. L'affermazione che scinde gli exempla dell'una e dell'altra lingua evidenzia come il greco non abbia alcunché da invidiare al latino in quanto ad ampiezza e fertilità del vocabolario. Se a ciò si aggiunge la discrepanza numerica tra gli esempi di entrambe le lingue e lo spazio riservato al commento dei passi aristotelici, non è irragionevole congetturare che Schopenhauer assecondi l'idea senecana che riconosce alla lingua greca una notevole ricchezza lessicale e una encomiabile pertinenza nella definizione dei concetti filosofici. Nel De ira, Seneca offre un primo elogio della sua subtilitas ${ }^{149}$,

144 SEN. nat. 2, 24, 2, p. 116.

145 Ibid., 3.

146 Schopenhauer stesso specifica che la frase è tratta dal trentasettesimo libro della Naturalis Historia $(\S$ 15).

147 ARIST. De Caelo, 294b, 6, p. 72; ibid., 298a, 12, p. 101; Ethica Magna, 1188b, 2 ss., p. 22.

148 ANACREON, Fragmenta, 17, 6 s. West (Ode 29 nel riferimento schopenhaueriano), p. 14 .

149 Cfr. SEN. ir. 1, 4, 2, p. 130: cetera quae pluribus apud Graecos nominibus in species iram distinguunt, quia apud nos vocabula sua non habent, praeteribo. Da un simile apprezzamento non bisogna però dedurre, per contrasto, un'affinità con il motivo della egestas linguae latinae di ascendenza lucreziana (LUCR. 1, 139, p. 12;1,831, p. 60;3, 260, p. 188). In realtà - e a dimostrarlo si dipana la successiva serie di qualificazioni della persona irata - Seneca si avvale della paralessi per poi cimentarsi, con successo, nel tentativo di rendere con termini latini vocaboli greci inerenti alla sfera semantica della

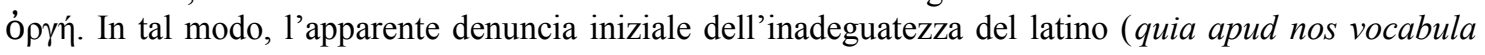


nel De beneficiis elogia l'acume linguistico dell'opera crisippea ${ }^{150}$ e nelle Naturales quaestiones rileva queste stesse doti - accanto alla robustezza delle argomentazioni all'interno dell'opera di Democrito, definito subtilissimus antiquorum omnium ${ }^{151}$.

\section{§ 4: I due problemi fondamentali dell'etica}

La prima citazione senecana nei Problemi è indiretta, e riporta il testo di un altro illustre pensatore che ricorre all'auctoritas del Cordovese, vale a dire Voltaire nel suo Le philosophe ignorant ${ }^{152}$. Schopenhauer - che qui propugna strenuamente la natura deterministica dell'azione umana contro l'idea di una presunta libertà del volere - cita Voltaire in un gruppo di tre filosofi (gli altri due sono Spinoza e Priestley), accomunati

sua non habent) si trasforma, di fatto, in uno sfoggio delle potenzialità lessicali che la lingua patria ha il potere di schiudere. Si tratta di un percorso argomentativo che accosta fortemente il pensiero senecano alla riflessione dell'Arpinate, il quale, dopo aver inizialmente sottolineato la vastità impareggiabile del patrimonio linguistico greco, non tarda ad individuarvi dei limiti, come nel caso della distinzione tra fatica e dolore: haec duo Graeci illi, quorum copiosior est lingua quam nostra, uno nomine appellant. Itaque industrios homines illi studiosos vel potius amantis doloris appellant, nos commodius laboriosos; aliud est enim laborare, aliud dolere. O verborum inops interdum, quibus abundare te semper putas, Graecia! (Tusc. 2, 35, Vol. I, p. 157). Più avanti, proprio a proposito delle affezioni, tra le quali figura ovviamente l'ira, al latino si riconosce addirittura una specificità terminologica per certi versi anche ignota al greco (ibid. 3, 7, Vol. II, p. 7). Lo stesso discorso è applicato ai concetti di amentia e dementia, insania e furor, libido e iracundia (ibid., 3, 10 s., Vol. II, p. 8). Secondo il giudizio ciceroniano, decisamente più netto di quello del Cordovese, nel vocabolario latino la lingua delle passioni resta oggetto di una ricerca più attenta e scandagliata: hoc propemodum verbo Graeci omnem animi

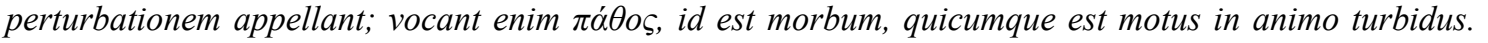
Nos melius: aegris enim corporibus simillima animi est aegritudo, at non similis aegrotationis est libido, non inmoderata laetitia, quae est voluptas animi elata et gestiens ... (ibid. 3, 23, Vol. II, p. 16). Di notevole sottigliezza è anche la preferenza accordata al termine latino convivium rispetto al greco $\sigma u \mu \pi$ ó $\mathbf{c}$ in una lettera ciceroniana indirizzata all'amico Lucio Papirio Peto (Ad familiares 9, 24, 3, Vol. II, p. 218), ennesima smentita dell'idea della povertà della lingua latina. Ad accomunare le due grandi voci dello stoicismo romano è dunque una fiducia di fondo, dissimulata attraverso un'iniziale preterizione, verso le potenzialità del latino nel traslare all'interno del proprio patrimonio linguistico il pensiero dei greci. Difficilmente il lettore più accorto potrebbe lasciarsi sfuggire la prontezza con cui Seneca sembra accogliere qui l'invito ciceroniano del De oratore (3, 95, Vol. III, p. 26): quamquam non haec ita statuo atque decerno, ut desperem Latine ea, de quibus disputavimus, tradi ac perpoliri; patitur enim et lingua nostra et natura rerum veterem illam excellentemque prudentiam Graecorum ad nostrum usum moremque transferri; sed hominibus opus est eruditis, qui adhuc in hoc quidem genere nostri nulli fuerunt; sin quando exstiterint, etiam Graecis erunt anteponendi. Nella Consolatio ad Polybium, oltretutto, accostando nuovamente la lingua madre a quella greca, il Cordovese rifugge da ogni idea di subordinazione dell'una all'altra, riconoscendo vigore alla prima ed eleganza alla seconda (Ad Polybium de consolatione, 2, 6, pp. 316 s.: ... quam diu steterit aut Latinae linguae potentia aut Graecae gratia ...). 150 Cfr. SEN. ben. 1, 3, 8, p. 7: Chrysippus quoque, penes quem subtile illud acumen est, et in imam penetrans veritatem, qui rei agendas causa loquitur, et verbis non ultra, quam ad intellectum satis est utitur.

151 SEN. nat. 7, 3, 2, p. 420.

152 SCHOPENHAUER, A., I due problemi fondamentali dell'etica - Memoria sulla libertà del volere, cap. IV: I precursori, p. 131. 
dal fatto di esser stati, in una prima fase, paladini della teoria del libro arbitrio, per poi convertirsi, nella maturità, alla logica e al linguaggio del determinismo. Il testo citato appartiene alla traduzione senecana in versi latini di un noto pensiero di Cleante: ducunt volentem fata, nolentem trahunt ${ }^{153}$. In altre parole, l'uomo perde ogni potere demiurgico sul proprio avvenire e su quello del mondo che lo ospita. Voltaire, come ha già modo di chiarire nel Trattato sulla tolleranza, vede nel verso di Seneca la quintessenza di "tutto il sistema della fatalità" 154 , e riporta l'esempio di Giove e della sua impossibiltà di intervenire per impedire la morte dell'amato figlio Sarpedonte (cui potremmo aggiungere, per citarne uno tratto sempre dalla tradizione greca e molto caro allo stesso Voltaire, quello di Edipo e del suo inutile tentativo di evitare con la fuga l'infausto destino di sposare la madre e uccidere il padre). Rafforzando l'efficacia del pensiero con la duplice opposizione costituita dalla coppia ducunt / trahunt e dall'antitesi volentem / nolentem, Seneca non fa che riprendere il lapidario eo ibis quae omnia eunt della lettera LXXVII $^{155}$, in cui, subito prima, ricorda il noto verso virgiliano desine fata deum flecti sperare precando ${ }^{156}$, rivolto dall'implacabile Sibilla cumana all'ombra di Palinuro: resta invariata la caratterizzazione del sapiens stoico come colui che riesce ad accettare e a tesaurizzare una verità così prostrante per ogni essere umano ${ }^{157}$.

Il verso della traduzione senecana ha assunto spesso valore paradigmatico per filosofi e letterati, sin da Agostino con la sua urgenza di subordinare alla voluntas di Dio lo stesso nesso causale degli accadimenti ${ }^{158}$, giungendo fino alla penna di Guicciardini, che addirittura, con riguardo alla citazione, scrive di non aver mai letto "cosa che mi

153 SEN. ep. 107, 11, Vol. II, p. 450.

154 VOLTAIRE, Trattato sulla tolleranza, p. 112, n. 122.

155 SEN. ep. 77, 12, Vol. I, p. 247.

156 VERGILIUS, Aeneis (d'ora in poi, VERG. Aen.), 6, 376, vol. II, p. 56.

157 Per il principio fatalità che veicola il nesso causale alla base delle sorti del mondo e per la sua presenza costante nell'arco dell'intera evoluzione del pensiero stoico, vd. POHLENZ, M., La Stoa, Vol. I, pp. $201 \mathrm{~s}$.

158 Cfr. AUG. De Civitate Dei, 5, 8, Vol. I, pp. 200 s.: qui vero non astrorum constitutionem, sicuti est cum quidque concipitur vel nascitur vel inchoatur, sed omnium conexionem seriemque causarum, qua fit omne quod fit, fati nomine appellant: non multum cum eis de verbi controversia laborandum atque certandum est, quando quidem ipsum causarum ordinem et quandam conexionem Dei summi tribuunt voluntati et potestati, qui optime et veracissime creditur et cuncta scire antequam fiant et nihil inordinatum relinquere; a quo sunt omnes potestates, quamvis ab illo non sint omnium voluntates. Ipsam itaque praecipue Dei summi voluntatem, cuius potestas insuperabiliter per cuncta porrigitur, eos appellare fatum sic probatur. Annaei Senecae sunt, nisi fallor, hi versus: (...) "Ducunt volentem fata, nolentem trahunt". Nempe evidentissime hoc ultimo versu ea fata appellavit, quam supra dixerat summi patris voluntatem; cui paratum se oboedire dicit, ut volens ducatur, ne nolens trahatur. 
paressi meglio detta" "159, e di Vettori che, nella sua lettera a Machiavelli del 23 novembre 1513, si richiama alle stesse parole per traslare il discorso dalla sfera umana ed esistenziale a quella politica ${ }^{160}$ : la decadenza o la prosperità dello Stato soggiacciono a dinamiche necessarie, a fronte delle quali ogni azione umana, in balia di un destino cui è totalmente estranea, non può alcunché. Particolarmente emblematica è l'immagine in riferimento alla quale Rabelais cita il verso nel suo Gargantua e Pantagruele ${ }^{161}$ : il primo dei due giganti lo trova scolpito su una delle due tavole di calamita incastrate tra $\mathrm{i}$ battenti e il muro del tempio della Bottiglia, e le parole senecane cancellano in lui il dubbio su come il portone del tempio stesso possa aprirsi e chiudersi senza una causa apparente: le lastre di calamita assoggettano alla loro forza le lame di acciaio che consentono la chiusura dei battenti, in quella che sembra una magnifica metafora dei fata che nolentem trahunt.

Seneca ricorre poi nella sezione del Fondamento della morale dedicata alla compassione naturale, fenomeno etico innato nell'essere umano che inizialmente può svilupparsi solo in negativo, cioè come risposta spontanea alle rappresentazioni del male che riserviamo ai nostri simili, offerte alla nostra coscienza per il tramite esperienziale e a fronte delle quali siamo portati umanamente a fermarci, obbedendo al principio neminem laedere. La svolta positiva della compassione interviene in una fase successiva e più matura, quella del passaggio dalla giustizia alla carità ${ }^{162}$. Spiegando il perché dello sviluppo in negativo, della sostanziale passività del primo grado di compassione, il filosofo di Danzica lo individua nella malitia che occupa la mente umana prima dell'intervento della bonitas, mutuando il pensiero senecano per cui ad neminem ante bona mens venit quam mala ${ }^{163}$. L'originaria inclinazione umana verso il male è ulteriormente sottolineata dal Cordovese in una lunga lettera sui compiti della filosofia, che può esplicare tanto un'azione terapeutica sull'animo malato perché impestato dai vizi quanto un'azione preventiva sull'animo sano ma per sua natura propenso ad

159 GUICCIARDINI, F., Ricordi, C138, , p. 767.

160 MACHIAVELLI, N., Epistolario, p. 422. In realtà, il Vettori varia l'espressione senecana in sed fatis trahimur.

161 RABELAIS, F., Gargantua e Pantagruele, cap. XXXVIII, p. 356.

162 Cfr. SCHOPENHAUER, A., I due problemi fondamentali dell'etica - Memoria sul fondamento della morale, § 17: La virtù della giustizia, pp. 279 ss.

163 SEN. ep. 50, 7, Vol. I, p. 132. 
peiora $^{164}$. Concordemente con Seneca, la tradizione stoica converge nel ritenere che solo il saggio possa esser spontaneamente spinto $(\pi \rho 0 \tau \varepsilon \tau \rho \alpha ́(\varphi \theta \alpha \imath)$ e spingere a sua volta

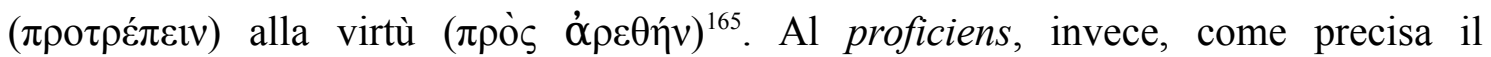
Cordovese nel testo immediatamente successivo a quello citato da Schopenhauer, è demandato l'arduo compito di percorrere i primi passi, cosa affatto semplice per un animo all'origine debole e instabile, che dunque andrà costretto (non è casuale l'uso del verbo cogere ${ }^{166}$ ) a iniziare: sembra riecheggiare in questo pensiero il celebre motto oraziano dell'epistola a Lollio dimidium facti, qui coepit, habet ${ }^{167}$, che sancisce l'invito a svegliarsi dal torpore (ut te ipsum serves, non expergisceris?) e a indirizzare l'animo verso azioni e pensieri improntati a rettidune (intendere animum studiis et rebus honestis $)^{168}$. Prima ancora di iniziare, però, è necessario che il proficiens ribalti un terreno irto di rovi e sterpaglie, per riportarlo a uno stadio di verginità primigenia, e assume una straordinaria pregnanza, in tal senso, il verbo impiegato da Seneca, più avanti nell'epistolario, per indicare questo sforzo preliminare di far tabula rasa delle esperienze passate: dediscere ${ }^{169}$, cioè “disimparare", riferito agli occhi - ma, in realtà, all'animo - di chi aspira alla sapientia ${ }^{170}$.

Sempre in rapporto alla compassione, Schopenhauer chiama in causa, ancora una volta, il velle non discitur senecano ${ }^{171}$, che già abbiamo avuto modo di riscontrare all'interno del Mondo, e che in questa sede si presta perfettamente a sintetizzare l'idea

164 SEN. ep. 94, 13, Vol. II, p. 367: duo sunt propter quae delinquimus: aut inest animo pravis opinionibus malitia contracta aut, etiam si non est falsis occupatus, ad falsa proclivis est et cito specie quo non oportet trahente corrumpitur. Itaque debemus aut percurare mentem aegram et vitiis liberare aut vacantem quidem sed ad peiora pronam praeoccupare. Utrumque decreta philosophiae faciunt (...).

165 VON ARNIM, H., Stoicorum veterum fragmenta, vol. III (d'ora in poi, SVF III), 682, p. $170 \mathrm{~s}$.

166 Cfr. SEN. ep. 50, 9, Vol. I, p. 132: sed quemadmodum virtutes receptae exire non possunt facilisque earum tutela est, ita initium ad illas eundi arduum, quia hoc proprium imbecillae mentis atque aegrae est, formidare inexperta; itaque cogenda est ut incipiat.

167 HOR. ep. 1, 2, 40, p. 47.

168 Ibid., 32 ss., p. 46.

169 Cfr. SEN. ep. 69, 2, Vol. I, p. 201: interrumpenda non est quies et vitae prioris oblivio; sine dediscere oculos tuos (...).

170 Un verbo molto simile è impiegato da Agostino per rendere un concetto analogo - proiettato ovviamente nell'orizzonte cristiano - nell'espressione dedocere mala, che indica la premessa imprescindibile al docere bona, sempre in virtù dell'impurità dell'animo umano (ricondotta, in base alla matrice cristiana, al peccato originale): illa femina rogasset, ut dignaretur mecum conloqui et refellere errores meos et dedocere me mala ac docere bona (AUG. Confessiones, 3, 12, 21, Vol. I, p. 62).

171 SEN. ep. 81, 13, Vol. I, p. 267. 
dell'innata diversità di carattere dei singoli individui, in risposta al dubbio legittimo sul perché la compassione stessa veicoli la condotta di alcuni ma non di altri ${ }^{172}$.

In realtà, la condotta umana si smembra in tre direttrici morali (egoismo, malvagità e, appunto, compassione), presenti in ogni individuo in proporizioni ben diverse, che vanno ad assecondare l'inclinazione caratteriale. Nel caso di quella malvagia, la smania incontenibile di recar danno al prossimo dovrà trovare appagamento anche a costo di mettere in pericolo la propria persona e i propri cari, e l'individuo perseguirà con una tale pervicacia l'obiettivo del dolore altrui da non temere le conseguenze del suo $^{173}$ : ... dum alteri noceat sui negligens ${ }^{174}$, scrive Schopenhauer citando l'apertura del primo libro del De ira di Seneca, in cui l'espressione è riferita proprio all'adfectus oggetto del trattato. Il ricorso al verbo neglego trasmette il senso di un autolesionismo irragionevole, in grado di spingere l'uomo anche fino alla morte (in ipsa inruens tela è la qualificazione immediatamente successiva). L'istintivo distacco dall'azione mediatrice della componente razionale, lo smarrimento della percezione di sé e dei pericoli e la corsa negligente e ostinata verso le conseguenze più nefaste sono tutti elementi già evocati, in forma embrionale, dal linguaggio epico, anche se in contesti non riferiti direttamente alla malvagità: si ricordi la reazione delirante della madre di Eurialo alla scoperta della sua morte, quando, ormai priva di controllo (amens), dimentica del rischio rappresentato dalle armi (non... pericli telorumque memor), prende a corrervi incontro come una forsennata $(\mathrm{cursu})^{175}$.

\section{$\S 5$ : Parerga e Paralipomena ${ }^{176}$}

La prima citazione di Seneca contenuta in Parerga e Paralipomena si trova nella Filosofia delle università, ed è volta a dimostrare come un suo asserto validissimo per i rapporti umani vada ribaltato se l'ambito di riferimento diventa il sapere filosofico:

172 Cfr. SCHOPENHAUER, A., I due problemi fondamentali dell'etica - Memoria sul fondamento della morale, § 20: Della differenza etica dei caratteri, pp. $322 \mathrm{~s}$.

173 Ibid., pp. 327 s.

174 SEN. ir. 1, 1, 1. p. 122.

175 VERG. Aen. 9, 478 ss., Vol. III, p. 23.

176 Per quanto riguarda la versione italiana dei Parerga, è notorio che quella integrale pubblicata dalla Adelphi segua l'edizione deusseniana - l'unica completa perché nata dalla collazione coi manoscritti e con gli Handexemplare - solo per il secondo tomo. Per i saggi inclusi nel primo, si è scelto di far riferimento a edizioni italiane pubblicate singolarmente e comprendenti le varie aggiunte. 
questo è passabile di progressi effettivi grazie ai (pochi) uomini che pensano per sé e non per gli altri, e se ciò, nella sfera morale - nei cui confini il filosofo di Danzica relega il discorso di Seneca - coincide con un bieco egoismo, in quella filosofica si traduce con un nobile anelito a creazioni della mente tanto elevate da sancire vittorie intellettuali a vantaggio dell'umanità intera. In realtà, il contenuto della citazione alteri vivas oportet, si vis tibi vivere ${ }^{177}$, se opportunamente inquadrato all'interno del pensiero senecano, oltrepassa i limiti della legge morale che - con un'innegabile anticipazione dell'etica cristiana - imporrebbe l'amore tra gli uomini (quell'amor mutuus ${ }^{178}$ cui Seneca fa riferimento altrove). Il monito rientra in un'apologia della coscienza sociale alla base della compartecipazione di interessi e sentimenti di cui l'amicizia - tema portante della prima parte dell'epistola - si sostanzia. Nel contesto della civitas, al cui interno l'uomo è indotto a operare a vantaggio dei suoi simili, analoghe affermazioni assumono una più o meno velata valenza civile. Questa chiave di lettura è corroborata da alcuni principi enunciati dal Cordovese nei suoi dialoghi, dal prodesse hominibus del De otio $^{179}$ alle indicazioni fornite del De tranquillitate animi a chiunque voglia giovare allo stato (prodesse rei publicae) anche dopo il proprio ritiro a vita privata ${ }^{180}$. Tale connotazione sociale non investe i soli filosofi, i quali, non necessitando dell'aiuto dei loro simili, lo offrirebbero in prima persona perché spinti da una necessità interiore ${ }^{181}$ risiede qui una differenza nevralgica rispetto al pensiero espresso da Schopenhauer in questa sede - ma assume un respiro ben più ampio, foriero di un decisivo superamento dell'individualismo epicureo, di quella filosofia che, come Seneca tiene ad evidenziare, civem extra patriam posuit, extra mundo $\operatorname{deos}^{182}$ (e il paragrafo della XLVIII lettera da cui Schopenhauer trae la citazione si apre proprio con una esplicita presa di distanza da Epicuro $^{183}$ ). Al pensiero senecano in esame sono sottesi due principi fondamentali della dottrina stoica. Il primo - che si rispecchia nella prima metà dell'asserto - è quello del

177 SEN. ep. 48, 2, Vol. I, p. 124.

178 SEN. ep. 95, 52, Vol. II, p. 395.

179 Cfr. SEN. ot. 3, 5, p. 166: hoc nempe ab homine exigitur, ut prosit hominibus, si fieri potest, multis, si minus, paucis, si minus, proximis, si minus, sibi. Nam cum se utilem ceteris efficit, commune agit negotium.

180 SEN. tr. an. 3, 3, p. 200: ita tamen delituerit ut, ubicumque otium suum absconderit, prodesse velit singulis universisque ingenio voce consilio.

$181 \mathrm{Su}$ questo aspetto vd. CIZEK, E., L'époque de Néron et ses controverses idèologiques, p. 260.

182 SEN. ep. 90, 35, Vol. II, p. 342.

183 Cfr. SEN. ep. 48, 2, Vol. I, p. 124: iterum ego tamquam Epicureus loquor? 
giovamento elargibile alla comunità, dell' $\dot{\omega} \varphi \varepsilon \lambda \varepsilon \tilde{\imath} v^{184}$, il secondo - che trova

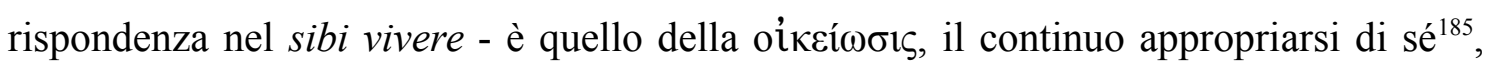
quella conciliazione affettiva col proprio essere e con tutto ciò che possa preservarlo, che nell'uomo, attraverso il filtro della ragione, si esplica anche come una naturale e sollecita cura del prossimo, garantendo l'amore reciproco tra i singoli: con assoluta

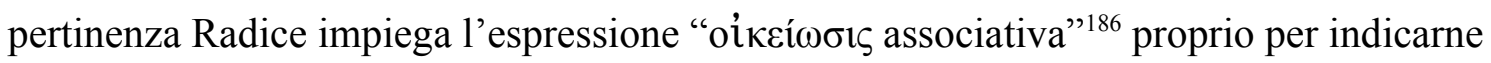
tale risvolto spiccatamente sociale. In altre parole, il vincolo di amore fra gli esseri umani, singoli tasselli di un'organica totalità, è attribuibile proprio alla loro discendenza da una medesima natura: è una humanitas attraverso cui l'individuo razionale non fa che assecondare e rispettare la sua essenza ${ }^{187}$. La humana vita così socialmente intesa risulta segnata, senza dubbio, dalla concezione ciceroniana ${ }^{188}$. Nel corso delle Epistulae ad Lucilium resta, tuttavia, ineguagliabile l'efficacia delle parole senecane, sia nella lapidaria constatazione che non continuo sibi vivit qui nemini ${ }^{189}$ (ep. 55, 5) sia nella similitudine tra la società e un arco di pietre che si sostengono a vicenda, dopo la rievocazione del verso terenziano homo sum, humani nihil a me alienum puto ${ }^{190}$ (cfr. ep. 95, 53). L'umiltà e il sentimento sociale insite nella globalità di questo discorso disegnano una dimensione dalla quale il filosofo, per forza di cose, non può essere avulso, come vorrebbe invece Schopehauer. Sempre nello stesso saggio, Schopenhauer si abbandona a una feroce critica contro quei presunti pensatori e in realtà semplici professori universitari che, a fronte degli sforzi compiuti da Hobbes, Spinoza, Priestley, Hume e, infine, anche da Kant per illustrare e sostenere il principio della necessità del volere, scelgono deliberatamente di ignorare oltre un secolo di evoluzione del sapere filosofico, traviando studenti e lettori con l'illusione che gli atti di volontà siano liberi. Riserva tuttavia a se stesso il merito di aver sintetizzato ed espresso nel miglior modo possibile il principio inconfutabile della necessità, e la sententia senecana conditio

184 Cfr. VON ARNIM, H., SVF III 74, p. 18.

185 Ibid. 179 , p. $43 ; 183$, p. 44.

186 RADICE, R., Oikeiosis. Ricerche sul fondamento del pensiero stoico e sulla sua genesi, $222 \mathrm{ss.}$

187 Per un'accurata analisi di questo concetto, vd. FIORE, G. M., Il concetto di educazione in Seneca, pp. 299 ss.

188 Cfr. CIC. fin. 3, 65, p. 115: quod nemo in summa solitudine vitam agere velit ne cum infinita quidem voluptatum abundantia, facile intellegitur nos ad coniunctionem congregationemque hominum et ad naturalem communitatem esse natos.

189 SEN. ep. 55, 5, Vol. I, p. 146.

190 Cfr. SEN. ep. 95, 53, Vol. II, p. 395. 
optima est ultimi ${ }^{191}$ allude alla posteriorità del suo intervento rispetto ai predecessori menzionati. Seneca rivela indiscutibilmente una modernità notevole nel considerare il patrimonio letterario scritto come un ricco bacino di pubblico dominio, con l'autore che perde, in qualche modo, la paternità del contenuto della sua opera: sulla scorta di questa convinzione, esorta Lucilio, in viaggio in Sicilia, a cimentarsi nella descrizione in versi dell'Etna, argomento già affrontato dal genio poetico di Virgilio, Ovidio e Cornelio Severo. L'amico e allievo non deve, tuttavia, lasciarsi intimorire dal confronto ma, anzi, avvalersi del vantaggio che gli deriva dalla possibilità di padroneggiare una materia brillantemente predisposta $\mathrm{e}$ che, da ultimo arrivato, dovrà solo riplasmare e reinventare secondo il proprio estro. Si tratta di un pensiero già espresso da Filodemo, il quale, nei frammenti del suo ampio trattato Sulla poesia, sostiene a più riprese un proficuo riuso dei modelli letterari, soprattutto per argomenti ben noti, evidenziando come, spesso, un rimaneggiamento della materia condotto con perizia, stile e personalità possa portare a risultati persino migliori delle opere precedenti ${ }^{192}$. È innegabile, però, che il Cordovese si sia appropriato appieno di questo principio, fino a rendersene testimonianza vivente con la sua opera, se si considerano i soggetti e i personaggi senza tempo al centro del corpus tragicum senecano.

La successiva citazione schopenhaueriana di Seneca figura in uno dei punti centrali della Speculazione trascendente sul destino del singolo. Schopenhauer presenta gli eventi come il possibile risultato dell'incontro-scontro tra due dimensioni di segno opposto, una fisica, dominata dalla casualità, e una trascendente, dominata dalla necessità, elemento quest'ultimo che non si può dimostrare ma solo desumere. Una volta compresa l'esistenza di una forza oscura e imperscrutabile che veicola i punti di snodo e quelli più critici della nostra esistenza assecondando la sua intrinseca finalità, spesso in modo contrario alle nostre inclinazioni immediate, non potremo che ridere della nostra miopia nell'aver nutrito desideri opposti a questa volontà suprema ${ }^{193}$. È a questo punto del discorso che, per suffragare la sua tesi, il filosofo di Danzica riporta

191 SEN. ep. 79, 6, Vol. I, p. 257.

192 Cfr. PHILOD. De poematis, 2, P. Herc. 1074, fr. 20, 16 ss., p. 89; P. Herc. 1081, fr. 6, 6 ss., p. 89; 3 , P. Herc. 1403, fr. 28, 15 ss., p. 89; per la ricostruzione del testo, si consultino sempre le pagine indicate. 193 Rimandiamo alla traduzione italiana presente in TAVANI E., (a c. di), Arthur Schopenhauer. Memoria sulle scienze occulte, pp. 56 ss. 
l'asserto ducunt volentem fata, nolentem trahunt ${ }^{194}$, di cui si è già diffusamente trattato a proposito delle sue ricorrenze nei Problemi.

All'interno degli Aforismi Seneca ricorre in più occasioni. La prima si rileva a proposito della contrapposizione tra gli individui di alta levatura intellettuale e spirituale e quelli ottusi e spiritualmente vuoti. In linea col tradizionale pessimismo schopenhaueriano, a fronte del malessere che attanaglia l'esistenza di entrambi, essa fluttua alla continua ricerca di una strategia per evitarlo o, quantomeno, attenuarne gli effetti. La differenza risiede nell'elemento motore di questo malessere. Nel primo caso, si tratta di individui la cui apertura al mondo esterno e interiore porta a un continuo fermento dei pensieri, sempre diversi nella natura e nelle combinazioni in base agli stimoli che li producono. Ne deriva una fantasia estremamente vivida, dalla quale scaturisce una maggiore intensità e incisività delle rappresentazioni, per cui tali indivui si rivelano predisposti a un'indole passionale, a una marcata amplificazione degli affetti e della sensibilità ai dolori, di natura sia fisica che interiore. Proprio per evitare i dolori, l'uomo intelligente e di animo nobile tenderà a cercare rifugio, sempre più nel tempo, in una vita modesta e appartata, fino alla totale solitudine, che non potrà certo turbarlo, perché la ricchezza e il fervore della sua mente irradieranno la propria forza anche nello spazio più deserto. La meschinità dell'altra categoria di individui, invece, li porta ad agire in modo diametralmente opposto, cioè a riempire il vuoto del proprio mondo interiore con tutto ciò che offre la realtà esterna, senza alcuna forma di selezione: proprio per questo motivo, l'unico criterio che seguono nella ricerca dei contatti umani è quello della quantità, senza curarsi del loro spessore morale. Trascorrono i momenti sgombri dalle necessità quotidiane a inseguire distrazioni e compagnia, anche se le distrazioni sono le più insulse e squalificanti e la compagnia è quella di uomini stolti quanto e più di loro. Il male di questi individui è la noia, sentimento che gli altri non conosceranno mai, perché si nutre della stupidità umana. La circostanza che cercano ostinatamente di evitare è proprio la solitudine, perché lì pone a tu per tu con la propria pochezza $^{195}$. Nessuna sententia - almeno fra quelle senecane - si presterebbe meglio a descrivere la loro condizione di quella scelta da Schopenhauer: omnis stultitia laborat

194 SEN. ep. 107, 11, Vol. II, p. 447. La citazione è ripetuta a poche pagine di distanza a proposito della convenienza di abbandonare un progetto quando è evidente che questo contrasti con la strada tracciata per noi dal destino (E. TAVANI, Arthur Schopenhauer ..., cit., p. 69).

195 Cfr. SCHOPENHAUER, A., Aforismi sulla saggezza della vita, cap. II: Di ciò che si è, pp. 48 ss. 
fastidio $s u i^{196}$. L'epistola da cui la massima è tratta è imperniata sull'autosufficienza del sapiens, che si realizza nell'otium e nel secessus e alla quale si oppone, proprio come nel discorso del filosofo di Danzica, la stupidità schiava della noia, che è fondamentalmente fastidio di sé, come recita la frase in esame. Quest'ultima sembra trovare una perfetta riformulazione nella lettera successiva, in apertura della quale si scongiura l'ipotesi che uno stolto possa esser lasciato solo, per i risvolti autolesionistici che potrebbero derivargli dal trovarsi in balia della sua miseria interiore, dei suoi bassi istinti e dell'odio verso se stesso: ipse se prodit ${ }^{197}$, sentenzia il Cordovese.

Per Schopenhauer, dolore e noia si qualificano, quindi, come le opposte estremità di un'esistenza necessariamente infelice. Alcune personalità riescono comunque a elevarsi oltre le esigenze estemporanee della volontà individuale, producendo un'energia intellettuale in grado di tesaurizzare il tempo libero e di riempirlo di senso ${ }^{198}$. In riferimento alle occupazioni che accompagnano questo continuo rigenerarsi dell'intelletto, il filosofo di Danzica ricorda che otium sine litteris mors est et homini vivi sepultura ${ }^{199}$, forse la sententia che meglio di tutte si presta a sintetizzare la concezione senecana dell'otium, dimensione esistenziale nota al solo sapiens e consacrata all'attività filosofica e letteraria, di cui il De otio finirà col rappresentare la concreta dimostrazione, un vero e proprio manifesto. Seneca fa riferimento in più di un'occasione all'esistenza di individui morti già in vita: sono coloro il cui otium è pura accidia, e che quindi sono da considerare loco (...) mortuorum $^{200}$, come certi grotteschi figuri che spesso si vedono sfilare per le vie dell'Urbe stesi sulle loro lettighe, ognuno dei quali aeger est, immo mortuus est ${ }^{201}$. Al di

196 SEN. ep. 9, 22, Vol. I, p. 22. La citazione ricorre a breve distanza con riguardo sempre allo stesso argomento e, con una riformulazione dovuta ad aeguamento sintattico, anche nei Pensieri diversi, allorché Schopenhauer evidenzia la miseria di chi non è dotato della facoltà di giudizio e della formulazione di pensieri propri: è una miseria assoluta e ai più incomprensibile fino in fondo, per cui è difficile farsi un'idea reale del fastidium sui, quo laborat omnis stultitia (SCHOPENHAUER, A., Pensieri diversi, ma ordinati sistematicamente su argomenti di vario genere - cap. 3: Pensieri riguardanti l'intelletto in generale e sotto ogni rapporto, $\S 48$, in ID., Parerga e Paralipomena - Vol. II, p. 88).

197 SEN. ep. 10, 2, Vol. I, p. 23.

198 Cfr. SCHOPENHAUER, A., Aforismi ..., cit., pp. $60 \mathrm{~s}$.

199 SEN. ep. 83, 2, Vol. I, p. 278.

200 SEN. ep. 60, 4, Vol. I, p. 167.

201 SEN., De brevitate vitae (d'ora in poi, br. v.), 12, 9, p. 286. 
fuori dell'iperbole ${ }^{202}$, l'idea della pericolosità di un otium scevro dalla dedizione alle litterae ricorre frequentemente tra le pagine senecane ${ }^{203}$.

Due richiami al De constantia sapientis figurano, a brevissima distanza fra loro, quando, sempre negli Aforismi, il filosofo di Danzica tratta l'argomento dell'onore, e a tal riguardo mette a confronto due sistemi di valori, due formae mentis, due orizzonti ideologici l'uno agli antipodi dell'altro: da una parte, è analizzato l'onore così come tramandato dai greci e dai romani, dall'altra quello del codice cavalleresco - estraneo a ogni contesto spaziale e cronologico al di fuori dell'Europa cristiana medievale - , la cui sintesi schopenhaueriana non nasconde toni divertiti e irrisori. Questa forma d'onore non si basa sulle parole e le azioni di un uomo, ma su ciò che gli accade e che subisce. Alla prima citazione Schopenhauer ricorre per qualificare in modo esemplare e sprezzante gli individui in balia dei quali può fluttuare l'onore - inteso in senso cavalleresco - anche dell'uomo più onesto e virtuoso, che si ritrova d'emblée disonorato per un loro insulto improvviso ${ }^{204}$ : ut quisque contemptissimus et ludibrio est, ita solutissimae linguae est ${ }^{205}$. Il secondo passo serve a dimostrare come, in base all'onore nella sua forma più tradizionale e più nobile che promana dalle pagine dei classici, l'offesa (contumelia) rappresenti una mera congiuntura collaterale da cui il saggio non potrebbe mai lasciarsi lambire ${ }^{206}$ (e non è un caso che Seneca citi la condotta un personaggio che, soprattutto nelle sue opere, assurge spessissimo a emblema assoluto di sapientia): at sapiens colaphis percussus, quid faciet? Quod Cato, cum illi os percussum esset: non excanduit, non vindicavit iniuriam, ne remisit quidem, sed factam negavit ${ }^{207}$.

Se l'onore è un parametro utile a valutare qualità morali che è lecito richiedere a tutti, la gloria riguarda fatti eccezionali e si spinge al di là dei rapporti privati e della conoscenza diretta. I fatti in questione possono essere azioni oppure opere. Le prime, in

202 Molto interessanti, al riguardo, sono le osservazioni sul topos della mortua vita offerte da Setaioli (SETAIOLI, A., Facundus Seneca. Aspetti della lingua e dell'ideologia senecana, p. 314 n. 218).

203 Cfr. SEN. br.v. 18, 2, p. 300: nec te ad segnem aut inertem quietem voco, non ut somno et caris turbae voluptatibus quicquid est in te indolis vividae mergas; non est istud adquiescere: invenies maiora omnibus adhuc strenue tractatis operibus, quae repositus et securus agites; ep. 55, 3, Vol. I, p. 145: multum (...) interest utrum vita tua otiosa sit an ignava; ep. 93, 3 Vol. II, p. 361: quid illum octoginta anni iuvant per inertiam exacti? non vixit iste sed in vita moratus est, nec sero mortuus est, sed diu.

204 Cfr. SCHOPENHAUER, A., Aforismi ..., cit., cap. IV: Di ciò che si rappresenta, p. 105.

205 SEN. const. sap. 11, 3, p. 94.

206 Cfr. SCHOPENHAUER, A., Aforismi ..., cit., pp. 111 ss.

207 SEN. const. sap. 14, 3, p. 102. 
quanto realtà pratiche fenomenologicamente inscritte in un dato segmento temporale, si prestano a esser recepite con notevole immediatezza, per cui è molto facile che un'azione meritevole riesca a procacciarsi la lode dei contemporanei, mentre ai posteri resterà il solo ricordo. Ben diverso è il destino delle opere - la cui genesi risiede esclusivamente nei rispettivi autori e non in una congerie di circostanze - perché diversa è la loro entità, estranea alla nozione di tempo e sempre uguale a se stessa: difficilmente potranno essere oggetto, sin dal principio, di giudizi attendibili, per mancanza o di competenza o di obiettività. Il tempo potrà solo offrire, eventualmente, qualche giudice valido, fautore di un verdetto giusto e definitivo (anche se ciò avviene, spesso, a distanza di secoli). Quanto più elevato è il valore di un'opera, tanto minore è la possibilità che il suo autore possa ottenere un riconoscimento in vita ${ }^{208}$. Nessuna affermazione si presta meglio a un simile contesto di quella, già citata nella Quadruplice, per cui etiam si omnibus tecum viventibus silentium livor indixerit, venient qui sine offensa, sine gratia iudicent ${ }^{209}$.

Ma nella stessa sezione dei Parerga Schopenhauer si confronta altresì con uno dei temi più cari al Cordovese, quello della temporalità e del rapporto che l'uomo vi instaura e, al di là della singola citazione che in un simile contesto non poteva certamente mancare, è impressionante, al riguardo, l'affinità contenutistica del discorso schopenhaueriano rispetto alla fonte. Non è certo questa la sede per esaminare la concezione del tempo in Seneca, che abbraccia decine di pagine tratte dalle sue opere più disparate ${ }^{210}$ (oltre, ovviamente al dialogus consacrato per intero all'argomento, il De brevitate vitae), ma non sarà difficile rinvenirne tracce tangibilissime in ciò che traspare dalle parole schopenhaueriane. La giusta constatazione di partenza del filosofo di Danzica è quella della necessità di un equilibrio, di un approccio sano e sereno rispetto alle tre dimensioni temporali, in particolare - escluso il passato che, come si evidenzia poco dopo, è fonte di rimpianti, pentimenti e insofferenza - il presente e il futuro, evitando gli estremi dell'incoscienza e della patologica apprensione che derivano rispettivamente da un'eccessiva incidenza dell'uno o dell'altro sulla vita quotidiana. Chi

208 Cfr. SCHOPENHAUER, A., Aforismi ..., cit., pp. 131 ss.

209 SEN. ep. 79, 17, Vol. I, p. 260.

210 Ritenendo riduttivo qualunque tentativo di selezione della copiosissima letteratura secondaria sull'argomento, ci limitiamo a rinviare alle pagine senecane sul tema del tempo opportunamente assemblate da TRAINA (Seneca, La brevità della vita. Con un'antologia di pagine sul tempo Commento di A. Traina, pp. 49 ss.). 
vive troppo proteso nel futuro tende, in effetti, a lasciarsi soverchiare da una vorace frenesia, che lo condanna a uno stato di inquietudine costante (in riferimento a tale categoria di individui, Seneca parla di aviditas nella stessa lettera da cui è tratta la frase che Schopenhauer si appresta a citare ${ }^{211}$, mentre, nel De brevitate, spiega che questa spasmodica attesa perdit hodiernum poiché pendet ex crastino $^{212}$ ). In tal modo, il presente non conosce attività, perché si proietta ogni azione e aspettativa nel quod futurum est di senecana memoria ${ }^{213}$. È dunque un presente che sfugge incompiuto man mano che diminuiscono gli istanti intercorrenti tra il giorno attuale e quello estremo (e proprio subito dopo il punto in cui si inquadra la citazione schopenhaueriana, Seneca sottolinea l'influenza delle vane speranze su questo stesso furto del tempo esistenziale ${ }^{214}$ ), mentre andrebbe vissuto nella sua pienezza: il totale e consapevole dominio dell'hic et nunc scaturisce dall'auspicabile convinzione che, rispetto al passato e al futuro, il presente sia l'unico tempo cui l'uomo può effettivamente metter mano ${ }^{215}$. È a questo proposito che Schopenauer arriva alla citazione esplicita del monito singulas dies singulas vitas puta $^{216}$, con il quale Seneca duplica l'invito, espresso nella prima parte dell'espistolario, a ordinare ogni giornata come se il suo compimento coincidesse con quello della propria esistenza ${ }^{217}$ : in una simile ottica, il sapiens è chi, come leggiamo nel De beneficiis, praesentibus gaudet, ex futuro non pendet $t^{218}$.

Due altri rimandi all'opera senecana si susseguono a proposito dell'invidia, di come essa costituisca un difetto pericoloso e devastante nella sua rara capacità di produrre frustrazione. Ancora una volta, già prima delle citazioni, il pensiero schopenhaueriano $^{219}$ si intreccia indissolubilmente e in modo inequivocabile a quello di Seneca, che, sempre nel De beneficiis, ha modo di qualificare l'invidia come il vizio più virulento e pernicioso (vehementius et importunius malum), che ci tormenta instillando

211 Cfr. SEN. ep. 101, 10, Vol. II, p. 423.

212 SEN. br. v. 9, 1, p. 274.

213 Ibid. 10, 2, p. 276.

214 Cfr. SEN. ep. 101, 10, Vol. II, p. 423: in spem viventibus proximum quodque tempus elabitur.

215 Cfr. SCHOPENHAUER, A., Aforismi ..., cit., cap. V: Esortazioni e massime, b) Del modo di comportarsi verso se stessi, pp. $164 \mathrm{~s}$.

216 SEN. ep. 101, 10, Vol. II, p. 423.

217 Cfr. SEN. ep. 12, 8, Vol. I, p. 28: (...) sic ordinandus est dies omnis tamquam cogat agmen et consummet atque expleat vitam.

218 SEN. ben. 7, 2, 5, p. 190.

219 Cfr. SCHOPENHAUER, A., Aforismi ..., cit., p. 185. 
il bisogno continuo di stabilire assurdi paragoni con chi riteniamo più fortunato di noi ${ }^{220}$. Le prime "belle parole" citate, che si inseriscono perfettamente nello stesso solco concettuale, sono nostra nos sine comparatione delectent; numquam erit felix quem torquebit felicior $^{221}$; insieme alle altre poc'anzi ricordate, trovano una sintesi perfetta nella sententia senecana quidiquid non adquiritur damnum est ${ }^{222}$. Assai simile è la citazione immediatamente successiva, cum aspexeris quot te antecedant, cogita quot sequantur $^{223}$ : essa sembra rispondere al celeberrimo quesito rivolto a Mecenate dall'Orazio satirico nel componimento proemiale, che condensa con impressionante sagacia le stesse peculiarità dell'invidia evidenziate sia da Seneca sia da Schopenhauer: qui fit, Maecenas, ut nemo, quam sibi sortem / seu ratio dederit seu fors obiecerit, illa / contentus vivat, laudet diversa sequentis? $?^{224}$.

La massima si vis tibi omnia subicere, te subice rationi ${ }^{225}$, già analizzata in occasione della sua ricorrenza nel Mondo, è riproposta con riguardo all'autocostrizione necessaria a sanare un'altra grande debolezza dell'animo umano: si tratta dell'attitudine a lasciarsi condizionare dalla continua collisione tra eventi diversi, accomunati solo dall'appartenenza al vissuto esistenziale della stessa persona e forieri di preoccupazioni che inibiscono la riuscita di qualunque opera e la capacità di affrontare in modo mirato nuove congiunture sfavorevoli ${ }^{226}$ (particolarmente efficace è l'immagine dei "cassetti di pensieri", da cui bisognerebbe trarre, di volta in volta, il problema cui far fronte lasciando chiusi tutti gli altri).

Il ricorso successivo all'auctoritas senecana concerne l'esortazione a non lasciarsi sedurre dalla maschera che, spesso, gli individui indossano in virtù della loro convenienza, celando subdolamente la propria reale natura: le persone non cambiano, si rivelano, e il modo migliore per non cadere nella trappola della dissimulazione è astenersi dalle opinioni affrettate che non poggiano su una solida conoscenza del proprio interlocutore ${ }^{227}$. È anche vero, però, che argumenta morum ex minimis quoque

220 Ibid. 2, 27, 3: invidia, quae nos inquietat, dum comparat. Subito prima, Seneca offre un ironico e amaro exemplum attinente la carriera politica: nemo agit de tribunatu gratias, sed queritur, quod non est ad praeturam usque perductus; nec haec grata est, si deest consulatus; nec hic quidem satiat, si unus est. 221 SEN. ir. 3, 30, 3, p. 312.

222 SEN. ep. 115, 16, Vol. II, p. 491.

223 SEN. ep. 15, 10, Vol. I, p. 41.

224 HOR. serm. 1, 1, 1 ss., p. 30.

225 SEN. ep. 37, 4, Vol. I, p. 101.

226 Cfr. SCHOPENHAUER, A., Aforismi ..., cit., pp. 193 s.

227 Ibid., 212 ss. 
licet capere $^{228}$ : esiste un linguaggio non verbale che, se opportunamente analizzato nelle sue minime componenti, può diventare uno specchio delle qualità morali di chi si ha dinanzi. Schopenhauer sceglie di ignorare l'argomento dei maestri retori e filosofi, che domina il contesto da cui l'affermazione senecana trae la sua ragion d'essere, e si limita a considerarla nella sua valenza assoluta: questo taglio generale rinvia a quanto Seneca afferma, più avanti nell'epistolario, quando introduce il "characterismos" come metodo per desumere vizi e virtù attraverso l'analisi di note esteriori distintive ${ }^{229}$. Seneca sembra aver assorbito, in parte, la lezione appresa dal padre che, nella praefatio al primo libro delle Controversiae, si lancia in una sferzante filippica contro la gioventù dei suoi giorni, invocando gli dei per scongiurare il rischio che essa possa costituire la classe oratoria degli anni a venire e passando in rassegna una serie di dati di natura fisiognomica che tradiscono indoli lascive e deprecabili, la cui qualificazione non necessita del linguaggio parlato ${ }^{230}$. Ma già Cicerone fa esplicito riferimento ad alcuni tratti del vestiario e dell'atteggiamento che riflettono sistemi di valori orientati ben oltre meri parametri estetici: ciò avviene sia nel De officiis - dove si analizza il significato femminile e maschile della bellezza, che si traduce in venustas nel primo caso e in dignitas nel secondo - sia nel De finibus, dove associa movimenti contorti o troppo sciolti e pose innaturali a menti arroganti o perverse ${ }^{231}$.

In una seconda ricorrenza ${ }^{232}$, la medesima massima senecana è impiegata da Schopenhauer per precisare che, se è vero che singoli pensieri e azioni sono già elementi altamente rivelatori del carattere, della natura di un uomo, lo sono a maggior ragione le piccolezze, perché sugli aspetti comportamentali più palesi anche gli individui più stolti riescono a mantenere un minimo livello di attenzione.

228 SEN. ep. 52, 12, Vol. I, p. 138. Il testo, in realtà, reca argumentum al posto della forma plurale, che non risulta attestata neppure sull'edizione delle Epistulae adottata da Schopenhauer (cfr. L. Annaei Senecae Philosophi opera omnia quae supersunt, rec. et ill. Fridericus Hernestus Ruckhopf - Vol. II, p. 226).

229 Cfr. SEN. ep. 95, 65 ss., Vol. II, pp. 398 ss. Il Cordovese offre un esempio del "characterismon” "ethologia" per Posidonio - attraverso una lunga descrizione di Platone come paradigma dell'uomo virtuoso, mettendone in luce tutti i tratti caratteristici di atteggiamento, portamento e postura.

230 Il retore si sofferma su dettagli quali i capelli sistemati, la voce modulata su toni femminili, le movenze sinuose, il corpo curato con eccessiva meticolosità, la pelle liscia e depilata (cfr. SENECA, L. A. $<$ RHETOR $>$, Controversiae 1, praef. 8 ss., p. 2 s.).

231 Cfr. CIC. fin. 5, 35, p. 172.

232 SCHOPENHAUER, A., Pensieri diversi ..., cit., cap. 8: Sull'etica, § 118, in ID., Parerga e Paralipomena - Vol. II, p. 304. 
L'argomento dell'esteriorità e dell'ipocrisia è particolarmente caro al filosofo di Danzica, che vi torna, sempre nella sezione degli Aforismi, per sottolineare come l'ostentazione di un qualunque pregio sia indice della sua stessa assenza, poiché la sicurezza di chi lo possiede gli rende superfluo esibirlo. E la maschera, prima o poi, cade di colpo, svelando tutta la miseria di chi la indossa ${ }^{233}$ : ecco che ricorre, in tutta la forza della sua verità, l'affermazione nemo potest personam diu ferre fictam $^{234}$.

La stessa, congenita debolezza della facoltà di giudizio alla base dei moniti rilevati sinora negli Aforismi legittima il ruolo imprescindibile dell'esempio morale, che Schopenhauer introduce nei Pensieri diversi, all'interno del capitolo Sull'etica ${ }^{235}$. Ma gli esempi possono solo favorire la manifestazione di determinate qualità, certamente non crearle ex nihilo, poiché per quello serve una reale motivazione interiore, ben radicata nella sfera morale del singolo individuo: non può che rinnovarsi l'incisività del velle non discitur senecano ${ }^{236}$.

Un'altra attitudine che certamente non si può apprendere è quella al pensiero autonomo. Un esempio lampante è offerto delle tante persone che, nelle controversie, cercano di sopperire alle loro chiare difficoltà argomentative attraverso citazioni di autori celebri, sostituendo l'intelletto di questi ultimi a quello di cui sono evidentemente sprovviste $^{237}$. La sententia unusquisque mavult credere quam iudicare ${ }^{238}$ sintetizza abilmente il concetto, per quanto nel testo senecano non figuri alcun collegamento con le citazioni dotte, ma ci si riferisca, in modo generico, ai danni derivanti dalla pigrizia di chi preferisce credere a tutto ciò che gli si dice e uniformare il proprio giudizio a quello delle folle o, comunque, degli antecedentes. La stigmatizzazione della stessa tendenza è già presente in Cicerone, che appella simili individui operarios barbarosque ${ }^{239}$.

L'impiego di questa massima, che ammanta il pensiero schopenhaueriano di una vaga coltre di aristocrazia intellettuale - concetto peraltro non estraneo al suo sistema

233 Cfr. SCHOPENHAUER, A., Aforismi ..., cit., pp. $218 \mathrm{~s}$.

234 SEN. clem. 1, 1, 6, p. 4. A differenza di quanto avviene per la citazione nel Mondo, in questo caso Schopenhauer riporta anche la frase immediatamente successiva, che ne completa appieno il senso: ficta cito in naturam suam recidunt.

235 SCHOPENHAUER, A., Pensieri diversi ..., cit., cap. 8: Sull'etica, § 119, in Parerga e Paralipomena, Vol. II, ... p. 315.

236 SEN. ep. 81, 13, Vol. I, p. 267.

237 Cfr. SCHOPENHAUER, A., Pensieri diversi ..., cit., cap. 22: Pensare da sé, § 266, in Parerga e Paralipomena, Vol. II, p. 659.

238 SENECA, L. A., De vita beata, 1, 4, p. 94.

239 CIC. Tusc. 5, 104, Vol. II, p. 151. 
già dal Mondo ${ }^{240}$ - ricorre nella postuma Eristische Dialektik ${ }^{241}$, come per informare di sé una sorta di testamento spirituale del Saggio di Francoforte.

\section{Bibliografia}

ANACREON. Fragmenta. in Carmina Anacreontea Edidit M. L. West. Stutgardiae et Lipsiae: In aedibus B. G. Teubneri, 1993.

ARISTOTELES. De caelo. in MOREAU, P. (ed.). Aristote. Du ciel. Paris: Les Belles Lettres, 1965.

ARISTOTELES. Ethica magna, in Aristotelis quae feruntur Magna Moralia, recognovit Franciscus Susemihl, Lipsiae: In aedibus B. G. Teubneri, 1883.

ARISTOTELES. Problemata, in LOUIS, P. (ed.), Aristote. Problèmes, Tomes I-III (3 voll.), Paris: Les Belles Lettres, 1991-1994.

AUGUSTINUS, Aurelius. Confessiones, in DE LABRIOLLE, P. (ed.), Saint Augustin. Confessions, Tomes I-II (2 voll.), Paris: Les Belles Lettres, 1925-1926.

AUGUSTINUS, Aurelius. De Civitate Dei, in Sancti Aurelii Augustini Episcopi De Civitate Dei Libri XXII recognoverunt Bernardus Dombart et Alfonsus Kalb (Editio quinta), 2 voll., Stutgardiae: In aedibus B. G. Teubneri, 1981.

AUGUSTINUS, Aurelius. De Genesi ad litteram, in AGAËSSE, P. - SOLIGNAC, A. (edd.), Oeuvres de Saint Augustin, Vol. 49: La Genèse au sens litteral en douze livres, Paris: Desclée de Brouwer, 1936.

AUGUSTINUS, Aurelius. Sermones de Scripturis, in Sancti Aurelii Augustini Hipponensis Episcopi Opera Omnia, post Lovaniensium theologorum recensionem, editio novissima, emendata et auctior, accurante J.P. Migne, Tomus quintus, Pars prior, Paris: venit apud editorem, 1841.

BACCHILIDES. Fragmenta, in Poetae lyrici graeci. Pars III, Poetae melici. Quartis curis recensuit Theodorus Bergk; editionis a. MDCCCLXXXII exemplar iteratum, indicibus ab Ioanne Rubenbauer confectis auctum, Lipsiae: in aedibus B. G. Teubneri, 1914.

BARTON, Carlin A. Roman Honor. The fire in the bones, Berkeley / Los Angeles: University of California Press, 2001.

BAXTER, Richard. The mischiefs of self-ignorance, and benefits of self-acquaintance, in ORME, W. (ed.), The practical works of Richard Baxter: with a life of the author and a critical examination of his writings by William Orme, Vol. 16, London: J. Duncan, 1830 .

240 Cfr. SCHOPENHAUER, A., Il mondo come volontà e rappresentazione, Vol. II, cap. 15: Delle imperfezioni essenziali dell'intelletto, p. 211.

241 SCHOPENHAUER, A., L'arte di ottenere ragione, Stratagemma 30, p. 108. 
BELLINCIONI, Maria. Il termine persona da Cicerone a Seneca, in ALLEGRI, G., [et al.], Quattro studi latini offerti a Vittore Pisani, Parma: Università degli Studi - Istituto di Lingua e Letteratura Latina, 1981, pp. 37-115.

CAESAR, Caius Iulius. De bello civili, in KLOTZ, A. (ed.), C. Iulius Caesar, Vol. II: Bellum civile, Monachi et Lipsiae: in aedibus K. G. Saur, 2006.

CAVALCA SCHIROLI, Maria Grazia (a c. di.). Lucio Anneo Seneca, De tranquillitate animi, Bologna: Clueb, 1981.

CHEVALLIER, Raymond. Montaigne, Lecteur de Sénèque, in Paideia, 54, 1999, pp. 95-113.

CICERO, Marcus Tullius. Ad familiares, in SHACKLETON BAILEY, D. R. (ed.), Cicero. Epistulae ad familiares, 2 voll. (Cambridge Classical Texts and Commentaries, 16-17), Cambridge: Cambridge University Press, 2004.

CICERO, Marcus Tullius. De finibus bonorum et malorum, in M. Tulli Ciceronis scripta quae manserunt omnia - Fasc. 43: De finibus bonorum et malorum libri quinque recognovit Th. Schiche, Lipsiae: In aedibus B. G. Teubneri, 1919.

CICERO, Marcus Tullius. De natura deorum, in M. Tulli Ciceronis Scripta quae manserunt omnia, Fasc. 45: De natura deorum post O. Plasberg edidit W. Ax. Editio stereotypa secundae, Stutgardiae: In aedibus B. G. Teubneri, 1961.

CICERO, Marcus Tullius. De officiis, in M. Tulli Ciceronis De officiis libri tres, recognovit Reinholdus Klotz, Lipsiae: Umptibus et typis B. G. Teubneri, 1866.

CICERO, Marcus Tullius. De oratore, in Cicéron. De l'orateur. Texte établi par Henri Bornecque et traduit par Edmond Courbaud, 3 voll., Paris: Les Belles Lettres, 1956.

CICERO, Marcus Tullius. Philippicae, in J. Gantrelle (ed.), M. Tullii Ciceronis in M. Antonium Oratio Philippica Secunda, Paris: Hachette, 1881.

CICERO, Marcus Tullius. Tusculanae disputationes, in Ciceronis Tusculanarum disputationum libri $V$ mit Benützung von Otto Heines Ausgabe, erklärt von Max Pohlenz, Stuttgart: B.G. Teubner, 1957.

CIZEK, Eugen. L'époque de Néron et ses controverses idèologiques, Leiden: Brill, 1972.

COLI, Daniela. Hobbes, Roma e Machiavelli nell'Inghilterra degli Stuart. Con la prima edizione italiana dei Tre Discorsi di Thomas Hobbes, Firenze: Le Lettere, 2009.

D'AGOSTINO, Vincenzio. Seneca e il De tranquillitate animi, in Athenaeum, 7, 1929, pp. 51-84.

DE MONTAIGNE, Michel, Saggi, trad. it., a c. di V. Enrico, Roma: Gherardo Casini Editore, 1953.

DIOGENES LAERTIUS. Vitae philosophorum, in MARCOVICH, M., (ed.), Diogenis Laertii Vitae philosophorum, Vol. I: Libri I-X, Stuttgart / Leipzig: B.G. Teubner, 1999.

DIRRIGL, Michael. Goethe und Schopenhauer: mit zwei Excursen, Regensburg: Universität-Verlag, 2000. 
DRYDEN, John. Absalom and Architophel, in HAMMOND, P. et al. (edd.), Dryden. Selected Poems, Harlow: Pearson Education Limited, 2007.

EPICTETUS. Dissertationes. in SOUILHÉ, J. (ed.), Épictète. Entretiens. Tome I: Livre I, Paris: Les Belles Lettres, 1945.

FIORE, Maria Grazia. Il concetto di educazione in Seneca, in FEDELI, P. (a c. di), Scienza, cultura, morale in Seneca - Atti del Convegno di Monte Sant'Angelo (27-30 settembre 1999), Bari: Edipuglia, 2001, pp. 285-302.

GIANCOTTI, Francesco. Seneca personaggio dell'Octavia, in Dioniso, 52, 1981.

GOETHE, Johann Wolfgang. Opere - vol. I, a c. di L. Mazzucchetti. Firenze: Sansoni, 1954.

GRILLI, Alberto. Il problema della vita contemplativa nel mondo greco-romano, Milano: Fratelli Bocca, 1953.

GUICCIARDINI, Francesco. Ricordi, in LUGNANI SCARANO, E. (a c. di), Opere di Francesco Guicciardini. Storie fiorentine, Dialogo del reggimento di Firenze, Ricordi e altri scritti, Torino: Unione Tipografico-Editrice Torinese, 1983.

HALL, John. Seneca as a source for earlier thought, in Classical Quarterly, 27, 1977, pp. 409-436.

HORATIUS (HORATIUS FLACCUS, Quintus). Epistulae, in VILLENEUVE, F. (ed.), Horace. Épitres, Paris: Les Belles Lettres, 1934.

HORATIUS (HORATIUS FLACCUS, Quintus). Sermones, in VILLENEUVE, F. (ed.), Horace. Satires, Paris: Les Belles Lettres, 1932.

HÜBSCHER, Arthur (hrsg. v.). Arthur Schopenhauer, Der handschriftliche Nachlaß in fünf Bänden, Bd. 5: Randschriften zu Büchern. München: Deutscher Taschenbuch Verlag, 1985.

JANKO, Richard (ed.). Philodemus - On poems, Vol. I/3, Oxford: Oxford University Press, 2011.

JOHNSON, Ben. Timber, or Discoveries, in DONALDSON, I. (ed.), Ben Johnson, Oxford: Oxford University Press, 1985.

KIERKEGAARD, Sören. Timore e tremore - Aut-Aut (Diapsalmata), trad. it., a c. di C. Fabro, Milano: BUR, $1998^{3}$.

KIERKEGARD, Sören. Skrifter - Bind 23 og K23, Journalerne NB15-NB20, red. CAPPELØRN, J. et al., Copenaghen: Gad, 2007.

LAUD, William, Sermon of the fast day, in SCOTT, W., et al. (ed.), The Works of the most reverend father in God, William Laud, Sometime Lord Archbishop of Canterbury, Vol. I: Sermons, Oxford: J. H. Parker, 1847.

LAUXTERMANN, Paul F. H. Schopenhauer's Broken World-View. Colours and ethics between Kant and Goethe, Dordrecht: Kluwer, 2000.

LEIGHTON, Robert. Sermon I (Romans XIII 11-14), in PEARSON, J. N. (ed.), The whole works of the Most Reverend Father in God, Robert Leighton: to which is prefixed a life of the author, London: H. G. Bohn, 1859. 
LUCRETIUS (LUCRETIUS CARUS, Titus). De rerum natura, in Lucreti De rerum natura. Locos praecipue notabiles collegit et illustravit Hector Paratore, commentario instruxit Hucbaldus Pizzani, Romae: in aedibus Athenaei, 1960.

MACHIAVELLI, Niccolò. Epistolario, in Montevecchi, A. (a c. di), Opere di Niccolò Machiavelli, vol. 3, Torino: Unione tipografico-editrice torinese, 1984.

MEWIS, Felix. De Senecae philosophi studiis litterarum. Dissertatio, Königsberg: Regimonti, 1908.

MUSIO, Andrea. (a c. di), Lucio Anneo Seneca, De ira. Libro primo. Testo, introduzione, traduzione e commento di Andrea Musio, Lecce: Pensa MultiMedia, 2013.

NIETZSCHE, Friedrich. Epistolario 1850-1869, Vol. I, trad. it. di M. Pampaloni Fama, a c. di G. Colli e M. Montinari, Milano: Adelphi, 1976.

NIETZSCHE, Friedrich. La filosofia nell'età tragica dei Greci, trad. it., a c. di F. Masini, Padova: Liviana, 1970.

NIETZSCHE, Friedrich. La gaia scienza, in G. Colli e M. Montanari (a c. di), Opere di Friedrich Nietzsche, Vol. V, tomo II, trad. it. di F. Masini, Milano: Adelphi, 1991².

PASOLI, Elio. Semel in anno licet insanire, in Latinitatis, vol. 6, no 4, 1958, pp. 247250.

PETRARCA, Francesco. Rerum senilium libri (I-VI), Vol. I, testo critico di E. Nota, Torino: N. Aragno Editore, 2004.

PHILIPPSON, Robert. Rezension zu M. Schäfer, Ein frühmittelstoisches System der Ethik bei Cicero, in Philologische Wochenschrift, 56, 1936.

PHILODEMUS. De pietate, in OBBINK, D. (ed.), Philodemus On Piety - Critical text with commentary, Oxford: Clarendon Press, 1996.

PHILODEMUS. De poematis, in JANKO, R. (ed.), Philodemus On Poems, Oxford: Oxford University Press, 2000.

PLATO. Cratylus, in MÉRIDIER, L. (ed.), Platon. Oeuvres complètes. Tome V, 2e partie: Cratyle, Paris: Les Belles Lettres, 1931.

PLATO. De legibus, in DES PLACES, E. - DIÈS, A. (edd.), Platon. Oeuvres complètes. Tomes XI-XII: Les Lois (4 voll.: Tome XI, 1re partie: Livres I-II; Tome XI, 2e partie: Livres III-VI; Tome XII, 1re partie: Livres VII-X; Tome XII, 2e partie: Livres XI-XII), Paris: Les Belles Lettres, 1951-1956.

PLATO. Gorgias, in CROISET, M. (ed.), Platon. Oeuvres complètes. Tome III, 2e partie: Gorgias, Ménon, Paris: Les Belles Lettres, 1923.

PLATO. Phaedrus, in MORESCHINI, C. (ed.), Platon. Oeuvres complètes. Tome IV, 3e partie: Phèdre, Paris: Les Belles Lettres, 1985.

PLATO. Protagoras, in CROISET, M. (ed.), Platon. Oeuvres complètes. Tome III, 1e partie: Protagoras, Paris: Les Belles Lettres, 1923.

PLUTARCHUS. De communibus notitiis, in CASEVITZ, M. (ed.), Plutarque. Oeuvres morales. Tome XV, 2e partie: Traité 72, Sur les notions communes, contre les Stö̈ciens, Paris: Les Belles Lettres, 2002. 
PLUTARCHUS. Lysander. in ANGELI BERTINELLI G. et al. (edd.), Le vite di Lisandro e di Silla, Milano: Mondadori (Fondazione Lorenzo Valla), 1997.

POHLENZ, Max. La Stoa, 2 voll, trad. it., Firenze: La Nuova Italia, 1967.

RABELAIS, François. Gargantua e Pantagruele, trad. it. a c. di A. Frassineti, Milano: BUR, 2010².

RADICE, Roberto. Oikeiosis. Ricerche sul fondamento del pensiero stoico e sulla sua genesi, Milano: Vita e Pensiero, 2000.

REALE, Giovanni. I problemi del pensiero antico. Le scuole ellenistico-romane, Milano: Celuc, 1973.

RENEHAN, Robert. A fragment of Alcaeus in Seneca?, in Rheinisches Museum, 112, 1969, pp. 187-188.

RUHKOPF, Friedrich Ernst (ed.). L. Annaei Senecae philosophi opera omnia quae supersunt. Recognovit et illustravit Fridericus Ernestus Ruhkopf - Vol. II, Lips: Weidmann, 1800.

SCARPAT, Giovanni. Parrhesia greca, parrhesia cristiana, Brescia: Paideia, 2001.

SCHÄFER, Maximilian. Ein frühmittelstoisches System der Ethik bei Cicero: Untersuchung von Ciceros drittem Buche De finibus bonorum et malorum, nach Aufbau und Zugehörigkeit auf Grund griechischer Quellen zur stoischen Ethik, München: Druck der Salesianischen Offizin, 1934.

SCHOPENHAUER, Arthur. Aforismi sulla saggezza della vita, trad. it., a c. di E. Battisti, Torino: Unione Tipografico-Editrice Torinese, 1970.

SCHOPENHAUER, Arthur. I due problemi fondamentali dell'etica, trad. it., a c. di S. Giametta, Milano: Mondadori, 2008.

SCHOPENHAUER, Arthur. Il mondo come volontà e rappresentazione, 2 voll., trad. it., a c. di S. Giametta, Milano: BUR, 2002.

SCHOPENHAUER, Arthur. Parerga e Paralipomena, Vol. II, trad. it. di E. Amendola Kuhn, Milano: Adelphi, 1998.

SCHOPENHAUER, Arthur. La quadruplice radice del principio di ragione sufficiente (1813), trad. it., a c. di A. Vigorelli, Milano: Guerrini e Associati, 1990, p. 165.

SCHOPENHAUER, Arthur. La quadruplice radice del principio di ragione sufficiente (1841), trad. it., a c. di E. Amendola Kühn, Torino: Boringhieri, 1959.

SENECA, Lucius Annaeus. Ad Polybium de consolatione, in Senecae Dialogi. Recognovit, adnotatione critica instruxit, italice reddidit Nedda Sacerdoti , Vol. II, Milano: Istituto Editoriale Italiano, 1971.

SENECA, Lucius Annaeus. Apocolocyntosis, in L. Annaei Senecae Divi Claudii

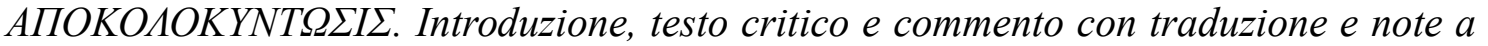
c. di C. F. Russo, Firenze: La Nuova Italia, 1970.

SENECA, Lucius Annaeus. De beneficiis, in L. Annaei Senecae Operae quae supersunt - Vol. I, Fasc. II: De beneficiis Libri VII. Edidit Carolus Hosius, Lipsiae: In aedibus B. G. Teubneri, 1900. 
SENECA, Lucius Annaeus. De brevitate vitae, in Senecae Dialogi. Recognovit, adnotatione critica instruxit, italice reddidit Nedda Sacerdoti - vol. II, Milano: Istituto Editoriale Italiano, 1971.

SENECA, Lucius Annaeus. De clementia, in CHAUMARTIN, F. R. (ed.), Sénèque. De la clémence. Nouvelle édition, Paris: Les Belles Lettres, 2005.

SENECA, Lucius Annaeus. De constantia sapientis, in Senecae Dialogi. Recognovit, adnotatione critica instruxit, italice reddidit Nedda Sacerdoti - vol. I, Milano: Istituto Editoriale Italiano, 1968.

SENECA, Lucius Annaeus. De ira, in Senecae Dialogi. Recognovit, adnotatione critica instruxit, italice reddidit Nedda Sacerdoti - vol. I, Milano: Istituto Editoriale Italiano, 1968.

SENECA, Lucius Annaeus. De otio, in Senecae Dialogi. Recognovit, adnotatione critica instruxit, italice reddidit Nedda Sacerdoti - vol. II, Milano: Istituto Editoriale Italiano, 1971.

SENECA, Lucius Annaeus. De providentia, in Senecae Dialogi. Recognovit, adnotatione critica instruxit, italice reddidit Nedda Sacerdoti - vol. I, Milano: Istituto Editoriale Italiano, 1968.

SENECA, Lucius Annaeus. De tranquillitate animi, in Senecae Dialogi. Recognovit, adnotatione critica instruxit, italice reddidit Nedda Sacerdoti - vol. II, Milano: Istituto Editoriale Italiano, 1971.

SENECA, Lucius Annaeus. De vita beata, in Senecae Dialogi. Recognovit, adnotatione critica instruxit, italice reddidit Nedda Sacerdoti - vol. II, Milano: Istituto Editoriale Italiano, 1971.

SENECA, Lucius Annaeus. Epistulae ad Lucilium, in L. Annaei Senecae Ad Lucilium Epistulae Morales, recognovit et adnotatione critica instruxit L. D. Reynolds, 2 voll., Oxonii: E Typographeo Clarendoniano, $1966^{2}$.

SENECA, Lucius Annaeus. Hercules furens, in L. Annaei Senecae Tragoediae. Recensuit et emendavit Fridericus Leo - Volumen secundum Senecae Tragoedias et Octaviam continens, Berlin: Weidmann, 1878.

SENECA, Lucius Annaeus. Naturales quaestiones, in P. Parroni (ed.), Seneca. Ricerche sulla natura, Milano: Mondadori, Fondazione Lorenzo Valla, 2002.

SENECA, Lucius Annaeus. Troades, in L. Annaei Senecae Tragoediae. Recensuit et emendavit Fridericus Leo - Volumen secundum Senecae Tragoedias et Octaviam continens, Berlin: Weidmann, 1878.

SENECA, Lucius Annaeus <RHETOR>. Controversiae, in L. Annaeus Seneca Maior, Oratorum et rhetorum Sententiae divisiones colores, recensuit L. Håkanson, Leipzig: Teubner, 1989.

SETAIOLI, Aldo. Facundus Seneca. Aspetti della lingua e dell'ideologia senecana, Bologna: Pàtron, 2000.

SETAIOLI, Aldo. Seneca e i greci. Citazioni e traduzioni nelle opere filosofiche, Bologna: Pàtron, 1988. 
TAVANI Elena (a c. di). Arthur Schopenhauer. Memoria sulle scienze occulte, Pordenone: Edizioni Studio Tesi, 1992.

TRAINA, Alfonso. Seneca, La brevità della vita. Con un'antologia di pagine sul tempo - Commento di A. Traina, Torino: Loescher, $2001^{8}$.

VERGILIUS (VERGILIUS MARO, Publius). Aeneis, in PERRET, J. (ed.), Virgile. Énéide, Tomes I-III (3 voll.). Paris: Les Belles Lettres, 1936-1977.

VOLTAIRE. Trattato sulla tolleranza. trad. it. a c. di L. Bianchi, Milano: Universale Economica Feltrinelli, 2010².

VON ARNIM, Hans (ed.). Stoicorum Veterum Fragmenta. Vol. III: Chrysippi fragmenta moralia, fragmenta successorum Chrysippi, Stutgardiae: in aedibus B. G. Teubneri, 1964. 